\title{
Mobilized Peripheral Blood versus Cord Blood: Insight into the Distinct Role of Proinflammatory Cytokines on Survival, Clonogenic Ability, and Migration of $\mathrm{CD}^{+}{ }^{+}$Cells
}

\author{
Dorian Forte $\mathbb{D}^{1,2}$ Daria Sollazzo, ${ }^{1}$ Martina Barone, ${ }^{1}$ Marisole Allegri, ${ }^{1}$ \\ Angela di Martella Orsi, ${ }^{1}$ Marco Romano, ${ }^{3}$ Barbara Sinigaglia, ${ }^{1}$ Giuseppe Auteri, ${ }^{1}$ \\ Nicola Vianelli, ${ }^{1}$ Michele Cavo, ${ }^{1}$ Francesca Palandri, ${ }^{1}$ and Lucia Catani ${ }^{1}{ }^{1}$ \\ ${ }^{1}$ Department of Experimental, Diagnostic and Specialty Medicine, University of Bologna, Bologna, Italy \\ ${ }^{2}$ Wellcome Trust-Medical Research Council Cambridge Stem Cell Institute and Department of Haematology, University of \\ Cambridge and National Health Service Blood and Transplant, Cambridge Biomedical Campus, CB2 OPT Cambridge, UK \\ ${ }^{3}$ School of Immunology \& Microbial Sciences, King's College London, Guy's Hospital, SE1 9RT London, UK \\ Correspondence should be addressed to Lucia Catani; lucia.catani@unibo.it
}

Received 21 February 2018; Revised 24 May 2018; Accepted 31 May 2018; Published 4 July 2018

Academic Editor: Elena Dozio

Copyright (C) 2018 Dorian Forte et al. This is an open access article distributed under the Creative Commons Attribution License, which permits unrestricted use, distribution, and reproduction in any medium, provided the original work is properly cited.

\begin{abstract}
Inflammation may play a role in cancer. However, the contribution of cytokine-mediated crosstalk between normal hemopoietic stem/progenitor cells (HSPCs) and their (inflammatory) microenvironment is largely elusive. Here we compared survival, phenotype, and function of neonatal (umbilical cord blood (CB)) and adult (normal G-CSF-mobilized peripheral blood (mPB)) $\mathrm{CD}^{+}{ }^{+}$cells after in vitro exposure to combined crucial inflammatory factors such as interleukin- (IL-) $1 \beta$, IL-6, tumor necrosis factor- (TNF-) $\alpha$, or tissue inhibitor of metalloproteinases-1 (TIMP-1). To mimic bone marrow (BM) niche, coculture experiments with normal BM stromal cells (BMSCs) were also performed. We found that combined inflammatory cytokines increased only the in vitro survival of $\mathrm{CB}$-derived $\mathrm{CD} 34^{+}$cells by reducing apoptosis. Conversely, selected combinations of inflammatory cytokines (IL- $1 \beta+$ TNF- $\alpha$, IL- 6 + TNF- $\alpha$, and IL- $1 \beta+$ TNF- $\alpha$ + TIMP-1) mainly enhanced the in vitro CXCR4driven migration of $\mathrm{mPB}$-derived $\mathrm{CD} 34^{+}$cells. TNF- $\alpha$, alone or in combination, upregulated CD44 and CD13 expression in both sources. Finally, BMSCs alone increased survival/migration of CB- and mPB-derived CD34 ${ }^{+}$cells at the same extent of the combined inflammatory cytokines; importantly, their copresence did not show additive/synergistic effect. Taken together, these data indicate that combined proinflammatory stimuli promote distinct in vitro functional activation of neonatal or adult normal HSPCs.
\end{abstract}

\section{Introduction}

Hemopoietic stem/progenitor cell (HSPC) activation and retention are modulated by the bone marrow $(\mathrm{BM})$ niche where they are located. In response to inflammation and/or BM injury, long-term quiescent hemopoietic stem cells (HSCs) are efficiently recruited into the cell cycle progression returning back to quiescence after reestablishment of homeostasis $[1,2]$. Inflammation is a fundamental response that protects tissues from damage and preserves internal homeostasis. However, chronic inflammation may hinder functionality of different tissues and has been suggested to cover a key role in cancer [3].

Proinflammatory cytokines are emerging as key regulators of steady-state and infection-driven hemopoiesis. Recent findings contributed to highlight how HSPC fate could be dictated by inflammatory factors in the BM microenvironment as HSPCs may actively respond to danger signals and proinflammatory cytokines $[4,5]$. However, excessive chronic signalling can have negative effects on HSPC regulation and function [6]. Moreover, abnormalities in the inflammatory signalling pathways have been discovered in both 
preleukemic and leukemic diseases [7]. BM mesenchymal stromal cells (BMSCs) are one of the most important components of the BM microenvironment. They respond to various microenvironment stimuli by changing their secretory capacity and displaying immune-suppressive activity through direct or indirect production of prostaglandin E-2, indoleamine 2,3-dioxygenase, interleukin- (IL-) 10 [8-10], and soluble receptors for IL- 1 and tumor necrosis factor- $\alpha$ (TNF- $\alpha$ ) [11]. However, a crosstalk between HSPCs and the stromal cells may also create a proinflammatory environment that promotes malignant transformation and disease progression [12]. In such process, several factors and pathways have been implicated but it is not clear how inflammation could affect or transform HSPCs. Understanding the direct cellular target(s) of proinflammatory cytokines is a critical step to better clarifying how HSCs/HSPCs are regulated in the BM niche.

Granulocyte colony-stimulating factor- (G-CSF-) mobilized peripheral blood $(\mathrm{mPB})$ and umbilical cord blood (CB) are two of the current sources of HSPCs for transplantation in hematological malignancies [13]; however, insights into the effects mediated by inflammation on neonatal and adult HSPCs are still elusive. In the last years, several phenotypic and functional differences between $\mathrm{CB}$ and $\mathrm{mPB}-$ derived HSPCs have been described [14-19]. However, so far, studies analyzing the adaptations of HSPCs from these two sources to inflammatory cytokines were focused on a limited number of cytokines which were individually tested [20-24].

To mirror the in vivo inflammatory microenvironment, here we investigated the role of combined crucial proinflammatory cytokines (IL- $1 \beta$, TNF- $\alpha$, IL-6, and tissue inhibitor of metalloproteases (TIMP-1)) on the in vitro functional behavior of $\mathrm{CB}$ - or $\mathrm{mPB}$-derived $\mathrm{CD} 34^{+}$cells in the presence or absence of BMSCs.

\section{Materials and Methods}

2.1. Sample Collection. CB samples $(n=14)$ from normal fullterm deliveries were provided by the Cord Blood Bank of the University Hospital of Bologna after written informed consent. $\mathrm{mPB}$ samples $(n=14)$ were obtained from hemopoietic stem cell transplantation donors. This study was approved by the medical Ethical Committee of the University Hospital of Bologna and was conducted in accordance with the Declaration of Helsinki.

2.2. Cell Isolation. Mononuclear cells (MNCs) were separated from $\mathrm{CB}$ and $\mathrm{mPB}$ samples (maximum after 1 day from harvesting) by stratification on Lympholyte- $\mathrm{H} 1.077 \mathrm{~g} / \mathrm{cm}^{3}$ gradient (Gibco-Invitrogen, Milan, Italy), followed by red blood cell lysis for $15 \mathrm{~min}$ at $4^{\circ} \mathrm{C}$. MNCs were then processed on magnetic columns for $\mathrm{CD} 34^{+}$cell isolation (mean purity $94 \pm 4 \%$ ) (CD34 Isolation kit; Miltenyi Biotec, Bologna, Italy), as previously described [25], and treated with our combination of cytokines on the same day. In selected cases, $\mathrm{CD}_{3} 4^{+}$cells from $\mathrm{CB}$ or $\mathrm{mPB}$ were cryopreserved in liquid nitrogen and then thawed before testing with the combined inflammatory cytokines. Of note, to minimize the influence of freezing/thawing, only thawed $\mathrm{CD} 34^{+}$cells with a survival rate $>80 \%$ were used and the thawed $\mathrm{CB} / \mathrm{mPB}$ cells were studied in the same experiment.

2.3. Phenotype of Circulating $\mathrm{CD} 34^{+}$Cells. The phenotype of circulating $\mathrm{CD} 34^{+}$cells was evaluated in $\mathrm{CB}$ and $\mathrm{mPB}$ samples by conventional flow cytometry, as previously described [20]. Antibodies used to characterize the $\mathrm{CD} 34^{+}$cells are listed in Supplementary Table 1. A minimum of $1 \times 10^{4}$ CD34 ${ }^{+}$cells were acquired by a BD Accuri C6 flow cytometer (Becton Dickinson, Milan, Italy). Analysis was performed excluding cellular debris in a SSC/FSC dot plot. The percentage of positive cells was calculated subtracting the value of the appropriate isotype controls. The absolute number of positive cells $/ \mu \mathrm{L}$ was calculated as follows: percentage of positive cells $\times$ white blood cell count/100.

2.4. Apoptosis Assay. Freshly isolated CD $34^{+}$cells $\left(2-5 \times 10^{5}\right)$ from $\mathrm{CB}$ units or $\mathrm{mPB}$ samples were maintained in RPMI 1640 with $10 \%$ fetal bovine serum (FBS), with or without IL-6 $(10 \mathrm{ng} / \mathrm{mL}), \mathrm{IL}-1 \beta(1 \mathrm{ng} / \mathrm{mL}), \mathrm{TNF}-\alpha(10 \mathrm{ng} / \mathrm{mL})$, and TIMP-1 $(100 \mathrm{ng} / \mathrm{mL})$, alone or in different combinations (all from Thermo Scientific, Rockford, IL, USA). After 24 hours, cells were stained for $15 \mathrm{~min}$ at RT with Annexin-VFLUOS Staining Kit (Roche, Penzberg, Germany). Samples were then immediately analyzed by a BD Accuri C6 flow cytometer. Results are expressed as percentage of live cells compared to the whole cells.

2.5. Erythroid and Granulocytic Progenitor Assays. CB/ $\mathrm{mPB}$-derived $\mathrm{CD} 34^{+}$cells were cultured in vitro to achieve hematopoietic cell differentiation and the formation of colony-forming units (CFU-Cs), which is the sum of colonyforming unit-granulocyte macrophage (CFU-GM) and erythroid burst-forming units (BFU-E). Specifically, CD34 ${ }^{+}$cells were seeded in methylcellulose-based medium (human StemMACS HSC-CFU lite w/ Epo, Miltenyi Biotech) at $5 \times 10^{2}$ cells $/ \mathrm{mL}$ in $35 \mathrm{~mm}$ Petri dishes in the presence or absence of the selected proinflammatory factors: IL-6 $(10 \mathrm{ng} / \mathrm{mL})$, IL-1 $\beta$ ( $1 \mathrm{ng} / \mathrm{mL})$, TNF- $\alpha$ (10 ng/mL), and TIMP-1 (100 ng/ $\mathrm{mL})$, alone or in combination. After 2 weeks of incubation at $37^{\circ} \mathrm{C}$ in $5 \%$ humidified $\mathrm{CO}_{2}$ atmosphere, CFU-C growth was evaluated by standard morphologic criteria using an inverted microscope (Axiovert 40, Zeiss, Milan, Italy).

2.6. Migration Assay. Migration of CB/mPB-purified CD34 $4^{+}$ cells was assayed in transwell chambers (diameter $6.5 \mathrm{~mm}$, pore size $8 \mu \mathrm{m}$; Costar, Corning), as previously described [25]. In order to highlight the effects of the selected inflammatory cytokines, suboptimal CXCL12 gradient (120 ng/ $\mathrm{mL}$ ) was employed. Briefly, $50 \mu \mathrm{L}$ of RPMI 1640 plus $10 \%$ FBS containing $0.5 \times 10^{5}$ cells was added to the upper chamber and $150 \mu \mathrm{L}$ of medium with or without CXCL12 \pm IL- 6 $(10 \mathrm{ng} / \mathrm{mL}), \quad \mathrm{IL}-1 \beta \quad(1 \mathrm{ng} / \mathrm{mL}), \quad \mathrm{TNF}-\alpha \quad(10 \mathrm{ng} / \mathrm{mL})$, and TIMP-1 (100 ng/mL) (alone or in combination) was added to the bottom chamber. After overnight incubation at $37^{\circ} \mathrm{C}$ in $5 \%$ humidified $\mathrm{CO}_{2}$ atmosphere, inserts (upper chambers) were removed and cells transmigrated into the lower chamber were recovered and counted by the Trypan Blue exclusion test. The amount of migrated cells was expressed as a percentage of the input, applying the following formula: 
(number of migrated cells recovered from the lower compartment/total number of cells loaded in the upper compartment $) \times 100$. In addition, migrated cells were assayed in methylcellulose-based medium for their ability to form hematopoietic colonies (as above described).

2.7. Isolation and Expansion of Mesenchymal Stromal Cells (BMSCs) from Healthy Donors (HD). BMSCs were obtained from $\mathrm{BM}$ aspirates collected from $\mathrm{HD}(n=3)$, as previously described [26]. BM-MNCs were separated by stratification on Lympholyte-H $1.077 \mathrm{~g} / \mathrm{cm}^{3}$ gradient (Gibco-Invitrogen) and then resuspended in culture medium (Dulbecco's modified Eagle's medium (DMEM) supplemented with $1 \%$ penicillin/streptomycin, L-glutamine, and 10\% FBS), plated, and maintained in a humidified incubator at $37^{\circ} \mathrm{C}$ and $5 \% \mathrm{CO}_{2}$. All nonadherent cells were removed after 24 hours. Medium was changed every 3-4 days until they reached 70-80\% confluence. Cells were then trypsinized (Lonza, Verviers, Belgium), replated at a density of 3500 cells $/ \mathrm{cm}^{2}$, and used for experiments within passages 3-4 after flow cytometry analysis for immunophenotype.

2.8. BMSCs Coculture Assay. In selected experiments, CBand $\mathrm{mPB}$-derived $\mathrm{CD} 34^{+}$cells were cocultured either without stromal support or directly seeded on a confluent layer of BMSCs in 96-well plates for 24 hours before use. CD34 ${ }^{+}$cells were then harvested and used to perform clonogenic and migration assay as above described; in addition, the selected cytokines were added to the bottom chamber. After overnight incubation at $37^{\circ} \mathrm{C}$ in $5 \%$ humidified $\mathrm{CO}_{2}$ atmosphere, cells transmigrated into the lower chamber were recovered and counted, as previously described.

2.9. Statistical Analysis. Data are presented as mean \pm SEM of at least three independent determinations. Statistical differences between groups were determined by a two-tailed Student $t$-test and one- or two-way ANOVA, as appropriate. All analyses were performed using GraphPad Prism software (version 6.0; La Jolla, CA, USA); $p \leq 0.05$ was considered to indicate statistical significance.

\section{Results}

3.1. Selected Combinations of Proinflammatory Cytokines Promote the In Vitro Survival of $\mathrm{CB}$-Derived $\mathrm{CD}_{3}{ }^{+}$Cells. To test the role of proinflammatory factors on HSPCs, we firstly evaluated the in vitro survival of CB- and $\mathrm{mPB}-$ derived $\mathrm{CD}_{3} 4^{+}$cells in the presence of IL- 6 , IL- $1 \beta$, TNF- $\alpha$, and TIMP-1, at concentrations previously shown by us to be effective in dose-response experiments [20].

Spontaneous survival rate of CB-derived $\mathrm{CD} 34^{+}$cells was higher as compared to $\mathrm{mPB}$ counterparts $(p \leq 0.05$; Figures 1(a) and 1(b)).

As shown in Figure S1, CB-derived CD34 ${ }^{+}$cell survival was further enhanced by TIMP-1, IL- $1 \beta$, and IL- 6 alone as compared with the $\mathrm{mPB}$ counterparts $(p \leq 0.05$; resp.). Compared to untreated cells (control), TIMP-1, IL- $1 \beta$, or IL- 6 alone poorly promoted the survival of $\mathrm{mPB}$ - and CBderived $\mathrm{CD}_{3} 4^{+}$cells with the notable exception of TNF- $\alpha$ which significantly $(p \leq 0.05)$ increased mPB-derived CD $34^{+}$ cell survival.

Therefore, based on these results and on data reported in literature $[20,25,27]$, we hypothesized that combinations of cytokines can make CB- or mPB-derived CD34 ${ }^{+}$ cells more responsive to inflammatory stimuli. As shown in Figure 1(a), when cytokines were two-by-two combined, we found that IL- $1 \beta+$ TNF- $\alpha(p \leq 0.01)$, IL- $6+$ IL- $1 \beta(p \leq 0.05)$, or TNF- $\alpha(p \leq 0.01)$ or TIMP-1 $(p \leq 0.01)$ significantly increased the percentage of viable $\mathrm{CB}$-derived $\mathrm{CD} 34^{+}$cells as compared with the untreated counterparts. In contrast, only IL- $1 \beta+$ TNF- $\alpha$ significantly increased the survival rate of mPB-derived CD34 ${ }^{+}$cells $(p \leq 0.001)$.

Testing multiple cytokine combinations (Figure 1(b)), the survival of $\mathrm{CB}$-derived and $\mathrm{mPB}$-derived $\mathrm{CD} 34^{+}$cells was significantly increased in the presence of IL- $1 \beta+$ TNF$\alpha+$ TIMP-1 $(p \leq 0.05$ and $p \leq 0.001$, resp. $)$ as compared with untreated cells. When we compared $\mathrm{CB}$ and $\mathrm{mPB}$ (Figures 1(a) and 1(b)), the survival rate of $\mathrm{CB}$-derived CD $34^{+}$cells was promoted in the presence of IL- $1 \beta+$ TIMP1 and IL- $6+$ TNF- $\alpha(p \leq 0.05)$.

These data suggest that $\mathrm{CD}_{3}{ }^{+}$cells from $\mathrm{CB}$ are more actively responsive to inflammatory cues than their $\mathrm{mPB}$ counterparts; however, multiple combinations are required to promote their survival.

Subsequently, we examined whether a combination of proinflammatory factors would trigger $\mathrm{CD} 34^{+}$progenitor cell differentiation. In selected experiments, freshly isolated CD34 ${ }^{+}$cells were cultured in RPMI medium supplemented with or without additional proinflammatory factors for 24 hours. The expression of selected myeloid-specific markers (CD11c, CD13, CD14, and CD45) along with HSPC markers (CD38, CD133) or specific marker for cell adhesion/proliferation (CD44) was analyzed by flow cytometry. The expression of CD11c, CD14, CD38, CD45, and CD133 was not significantly affected by inflammatory factor treatment (data not shown). By contrast, after treatment with combined inflammatory cytokines, $\mathrm{mPB}$ - and $\mathrm{CB}$-derived $\mathrm{CD} 34^{+}$cells upregulated the expression of CD13 and CD44 (Figures 1(c) and $1(\mathrm{~d})$ and Supplementary Table 2$)$. After treatment with IL- 6 + IL- $1 \beta+$ TNF- $\alpha+$ TIMP-1, CB-derived CD $34^{+}$cells showed a 5 -fold increase in geometric mean fluorescence intensity (gMFI) of CD13 as compared to untreated cells (gMFI, $p \leq 0.001$ ). Accordingly, a statistically significant difference was also found in the presence of IL- $1 \beta+$ TNF- $\alpha$ or IL- $6+$ TNF- $\alpha \pm$ IL- $1 \beta$ (4.41- and 4.64-fold change; $p \leq$ 0.001 , resp.). A similar pattern was also found when $\mathrm{mPB}$ $\mathrm{CD} 34^{+}$cells were tested (Figure $1(\mathrm{c})$ ).

Consistent with CD13 expression, the combination of IL- $1 \beta+$ TNF- $\alpha \quad(p \leq 0.01)$ and IL- $6+$ IL- $1 \beta+$ TNF- $\alpha$ ( $p \leq$ $0.05) \pm$ TIMP-1 $(p \leq 0.01)$ induced a significantly higher CD44 expression in CB-derived $\mathrm{CD}_{4}{ }^{+}$cells (>2-fold increase, respectively; Figure $1(\mathrm{~d})$ ). When we evaluated the mPB-derived CD $34^{+}$cells, CD44 expression markedly increased in the presence of IL- $\beta+$ TNF- $\alpha(p \leq 0.001)$, IL- $6+$ TNF- $\alpha(p \leq 0.01)$, and the combination of cytokines altogether $(p \leq 0.001)$. Importantly, TNF- $\alpha$ alone increased the expression of CD13 and CD44 in CD34 ${ }^{+}$cells from both sources (Figure S2; $p \leq 0.001$ ). 


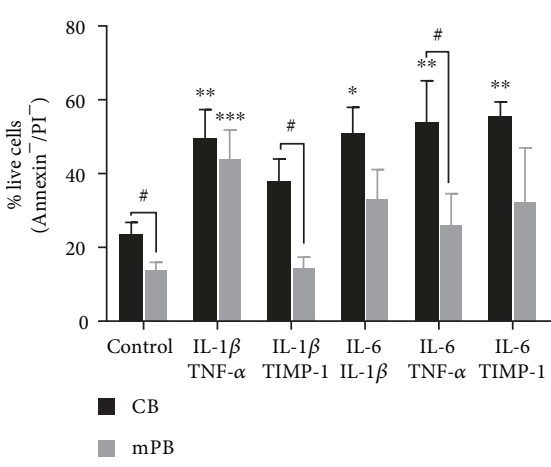

(a)

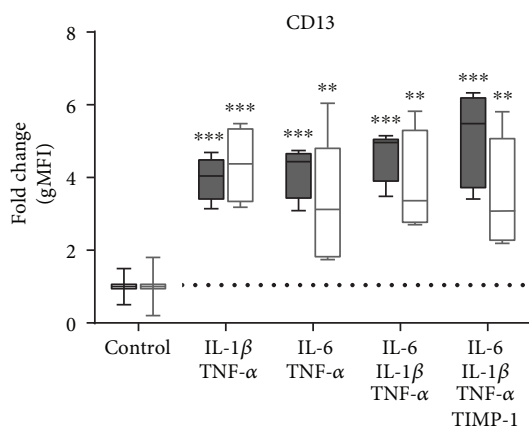

ㄷ $\mathrm{CB}$

$\square \mathrm{mPB}$

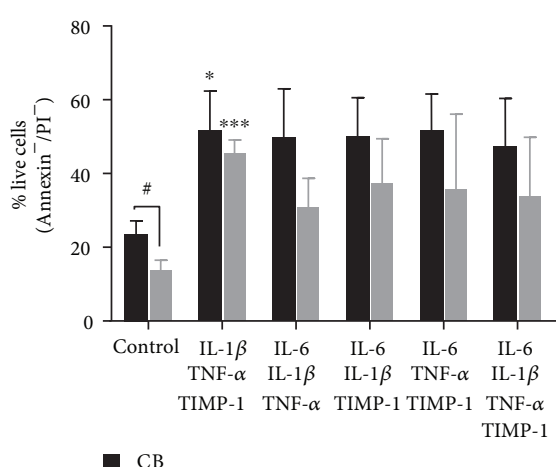

(b)

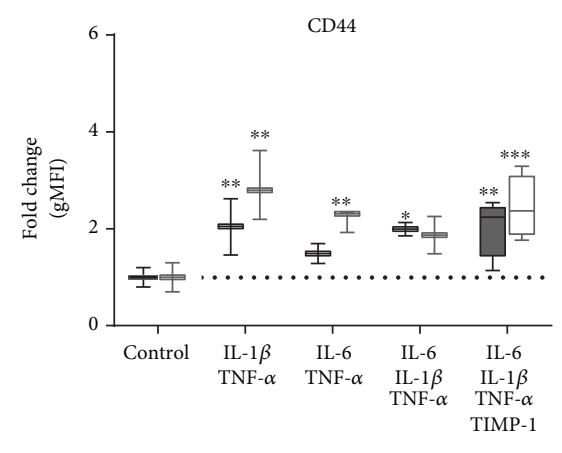

- $\mathrm{CB}$

$\square \mathrm{mPB}$

(c)

(d)

Figure 1: Survival and phenotype of $\mathrm{CD} 34^{+}$cells from $\mathrm{CB}$ or $\mathrm{mPB}$ in the presence of combined proinflammatory cytokines. (a) Percentage of live $\mathrm{CD} 34^{+}$cells from CB (indicated as negative for Annexin V and PI (black columns, $n=9$ ) or mPB (grey columns, $n=8$ ) in vitro treated for 24 hours with a two-by-two-factor combination and assessed using Annexin V/PI staining, as described in Methods. (b) Percentage of live $\mathrm{CD} 34^{+}$cells in the presence of multiple combinations of proinflammatory cytokines. (c-d) Box-plot graphs with fold change of gMFI for $\mathrm{CD} 13$ and $\mathrm{CD} 44$ expression in $\mathrm{CD}_{4} 4^{+}$cells after treatment with different combinations of inflammatory cytokines. Dot lines were used to mark control samples without any treatment. All data are presented as mean \pm SEM of $n$ (as above described) experiments performed in duplicate $\left({ }^{*} p \leq 0.05,{ }^{* *} p \leq 0.01\right.$, and ${ }^{* * *} p \leq 0.001$ versus untreated cells (control)). $\left({ }^{\#} p \leq 0.05 \mathrm{CB}\right.$ versus mPB).

Taken together, these results demonstrate that selected combinations of inflammatory cytokines, along with the promotion of the survival of $\mathrm{CB}$-derived $\mathrm{CD} 34^{+}$cells, stimulate the expression of CD13, which is an early and late myeloid marker.

\subsection{Proinflammatory Cytokines Poorly Stimulate the} Clonogenic Output of $\mathrm{CD}_{3} 4^{+}$Cells from $C B$ and $\mathrm{mPB}$. To confirm the capacity of selected proinflammatory cytokines to drive the HSPCs toward a myeloid lineage, we performed clonogenic assay.

We therefore evaluated the CFU-C growth in the presence of proinflammatory factors in a two-by-two combination. As shown in Figure 2(a) and Supplementary Table 3, CFU-C growth from $\mathrm{CB}$ or mPB-derived $\mathrm{CD} 34^{+}$cells was not significantly affected by incubation with the proinflammatory cytokines as compared with untreated cells. When we used multiple combinations of cytokines (Figure 2(b)), we found an increased clonogenic output in the presence of IL- $1 \beta+$ TNF- $\alpha+$ TIMP- 1 for CBderived $\mathrm{CD}_{3} 4^{+}$cells and in the presence of IL- $6+\mathrm{IL}-$
$1 \beta+$ TIMP-1 for the mPB counterparts $(p \leq 0.05$, resp.). Comparing the two sources, IL- $\beta+$ TNF- $\alpha+$ TIMP- 1 led to an increase in the clonogenic output of $\mathrm{CD} 34^{+}$ cells $(p \leq 0.05)$.

Of note, when colony composition was analyzed, no significant difference was observed in the CFU-GM growth (Figures 2(c) and 2(d)) between treated and untreated cells with the notable exception of IL-6 + TIMP-1 for mPBderived CD34 ${ }^{+}$cells $(p \leq 0.01)$. Moreover, comparing the two sources, the CFU-GM growth of the mPB-derived CD $34^{+}$cells was significantly enhanced by IL- $6+$ TNF- $\alpha$ $(p \leq 0.05)$. As regards the erythroid lineage (Figures 2(e) and 2(f)), only IL- $1 \beta+$ TNF- $\alpha+$ TIMP- 1 significantly promoted the BFU-E growth of $\mathrm{CB} \mathrm{CD} 34^{+}$cells as compared to untreated cells and the $\mathrm{mPB}$ counterparts ( $p$ $\leq 0.01$ and $p \leq 0.05$, resp.). Interestingly, in the presence of IL- $6+$ TNF- $\alpha \pm$ IL- $1 \beta$, we found a statistically significant decrease in BFU-E growth of $\mathrm{mPB} \mathrm{CD} 34^{+}$cells compared to untreated cells $(p \leq 0.05)$. Of note, IL- $6+$ TNF- $\alpha$ show opposite effects on the erythroid and granulomonocyte progenitors of $\mathrm{mPB}$-derived $\mathrm{CD}^{+} 4^{+}$cells by enhancing 

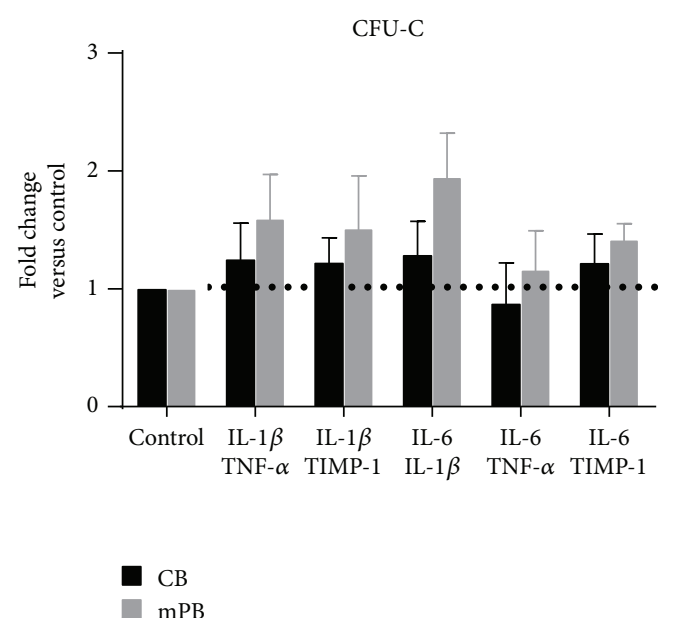

(a)

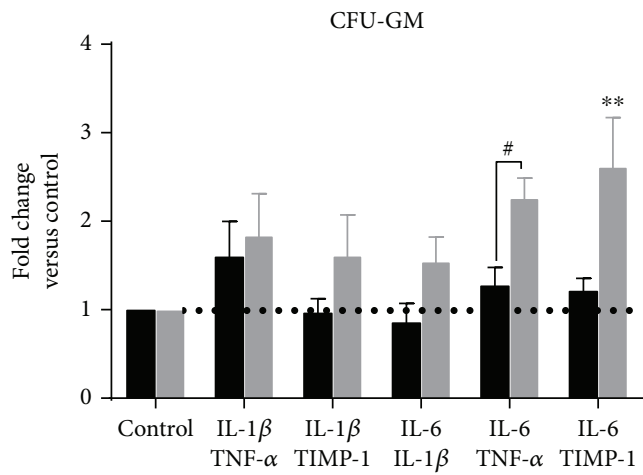

a $\mathrm{CB}$

mPB

(c)

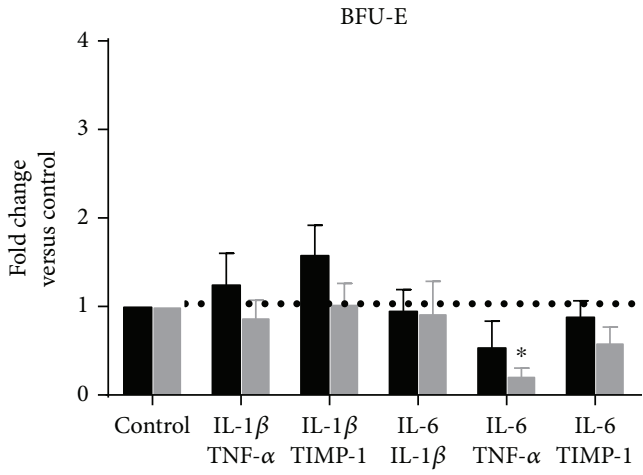

- $\mathrm{CB}$

$\mathrm{mPB}$

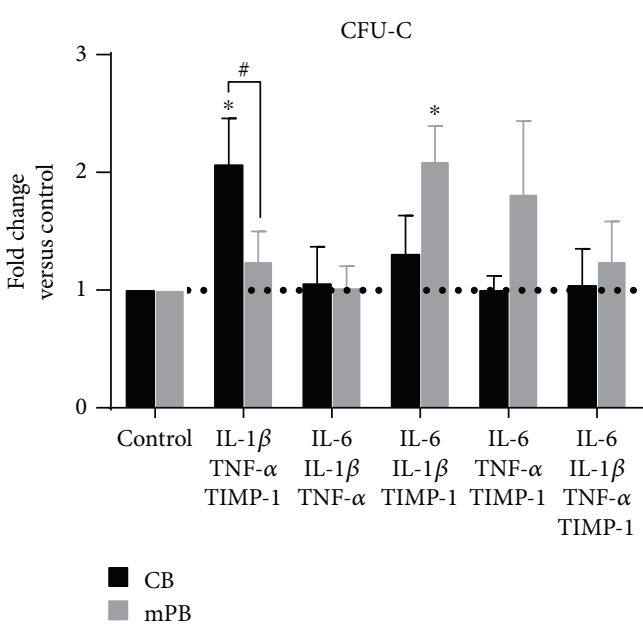

(b)

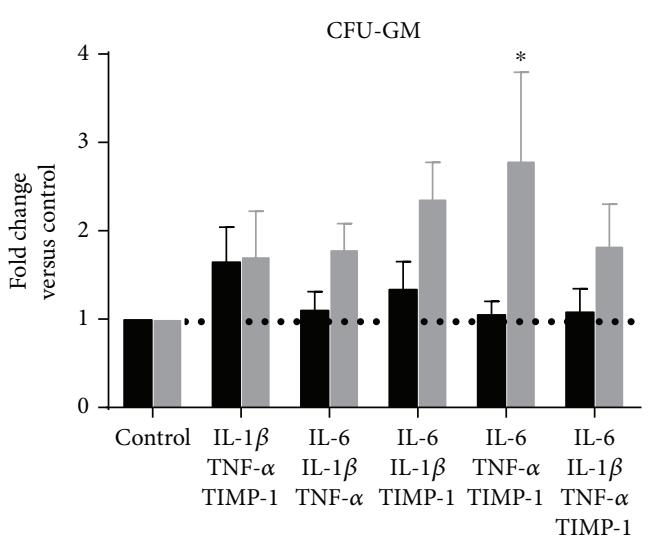

- Св

$\mathrm{mPB}$

(d)

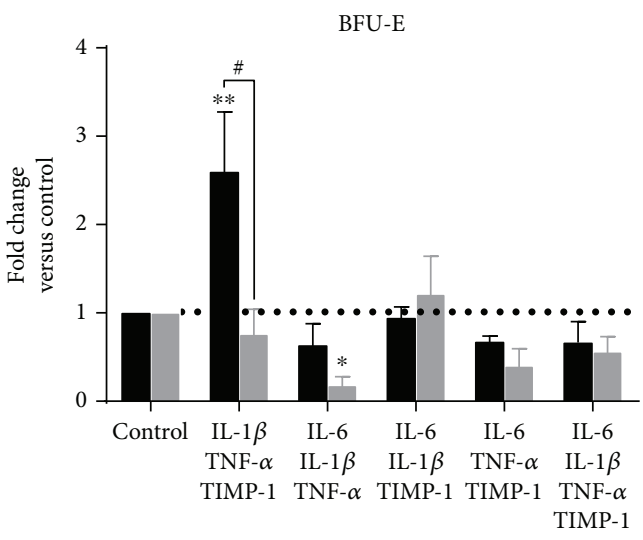

- $\mathrm{CB}$

$\mathrm{mPB}$

(e)

FIGURE 2: Clonogenic output of CB- and mPB-derived CD34 ${ }^{+}$cells after combined inflammatory stimuli treatment. Comparison of CFU-C formation between CB- ( $n=9$ independent experiments) and mPB-derived ( $n=10$ independent experiments) CD34 ${ }^{+}$cells cultured for 14 days in methylcellulose-based medium is shown. The total CFU-C output was assessed in the presence of inflammatory cytokines with the two-by-two combination (a) or multiple combinations (b). The CFU-GM (c-d) and BFU-E (e-f) output was assessed. The results are expressed as growth fold change of inflammatory cytokine-treated versus untreated cells (control). Control samples were marked with a dot line. All data are presented as mean \pm SEM $\left({ }^{*} p \leq 0.05,{ }^{* *} p \leq 0.01\right.$ versus untreated cells (control)). $\left({ }^{\#} p \leq 0.05 \mathrm{CB}\right.$ versus mPB). 
CFU-GM (Figure 2(c)) and inhibiting BFU-E growth (Figure 2(e)).

To further investigate, we next examined the subtype compartment of CFU-GM and BFU-E as percentage of total $\mathrm{CFU}$ (Figure S3). As shown in Figure S3(A) and (B), we found that, after treatment with IL- $6+$ TNF- $\alpha \pm$ IL- $1 \beta+$ TIMP-1, the CFU-GM growth of $\mathrm{CB} \mathrm{CD} 34^{+}$cells was highly promoted $(78.8 \pm 8.4 \%$ and $74.5 \pm 6.8 \%$ compared to $57 \% \pm 3.2$ of untreated cells; $p \leq 0.05$, resp.), whereas it decreased in the presence of IL-1 $\beta$ + TNF- $\alpha$ + TIMP-1 (43.4 $\pm 3.7 ; p \leq 0.05)$. No significant effects were observed when $\mathrm{mPB} \mathrm{CD} 34^{+}$cells (Figure S3(C) and (D)) were analyzed.

These findings demonstrate that inflammatory cytokines slightly stimulate the hemopoietic functions of CB- and mPB-derived HSPCs.

\subsection{Selected Combinations of Inflammatory Cytokines Mainly} Enhance the In Vitro Migration of $m P B$-Derived $C D 34^{+}$Cells. It has been reported that CXCL12 is chemotactic for CD $34^{+}$ cells and that the migratory behavior of $\mathrm{CD} 34^{+}$cells depends on their source of origin [28].

We firstly evaluated CXCR4 expression in CB- and $\mathrm{mPB}$ $\mathrm{CD} 34^{+}$cells. As shown in Figure 3(a), the absolute number of $\mathrm{CD} 34^{+}$cells coexpressing CXCR4 was significantly increased in $\mathrm{mPB}$ as compared with the CB counterparts $(p \leq 0.01)$. Accordingly, we observed a slight increase in the geometric mean value of CXCR4 in mPB CD34 ${ }^{+}$cells as compared to CB-derived CD $34^{+}$cells (Figures 3(b) and 3(c)).

Subsequently, we compared spontaneous versus CXCL12driven migration and no significant differences were found in the migration rate when CXCL12 was added in culture (Figures 3(d) and 3(e)). This was probably due to the fact that, to highlight the effects of the inflammatory cytokines, low CXCL12 dose $(120 \mathrm{ng} / \mathrm{mL})$ was used.

To study the role of proinflammatory cytokines in the modulation of spontaneous or CXCL12-mediated migration, we set up the in vitro migration of CB- or mPBderived $\mathrm{CD} 34^{+}$cells in the presence of CXCL12 alone or CXCL12 plus selected combinations of proinflammatory cytokines (Figures 3(d) and 3(e)). As compared to the spontaneous migration, $\mathrm{CD} 34^{+}$cells from $\mathrm{mPB}$ showed increased migration ability toward CXCL12 when IL- $1 \beta+$ TNF- $\alpha$, IL$6+$ TNF- $\alpha$ ( $p \leq 0.05$, resp.), and IL- $1 \beta+$ TNF- $\alpha+$ TIMP- 1 or IL- $6+$ TNF- $\alpha+$ TIMP- $1 \quad(p \leq 0.01$, resp. $)$ were added. IL- $6+$ TNF- $\alpha+$ TIMP- $1 \pm$ IL- $1 \beta$ significantly increased the migration of the $\mathrm{CBCD} 34^{+}$cells ( $p \leq 0.01$, resp.). As compared to migration toward CXCL12 alone, only IL- $1 \beta+$ TNF- $\alpha$ or IL- $6+$ TNF- $\alpha$ significantly enhanced the migration of mPBderived CD $34^{+}$cells $(p \leq 0.05$ and $p \leq 0.01$, resp.). The migratory capacity toward CXCL12 of $\mathrm{CB}$ CD $34^{+}$cells was promoted only by IL- $6+$ TNF- $\alpha+$ TIMP- $1+$ IL- $1 \beta$ ( $p \leq$ 0.05 ). Comparing the two sources, the migration rate of $\mathrm{CD} 34^{+}$cells from $\mathrm{mPB}$ was significantly enhanced when CXCL1 $2+$ IL- $1 \beta+$ TNF- $\alpha \pm$ TIMP-1 $\quad(p \leq 0.05$, resp. $)$ and CXCL1 $2+$ IL- 6 + TNF- $\alpha(p \leq 0.05)$ were added to the lower transwell chamber.

These results demonstrate the capacity of selected combinations of inflammatory cytokines to increase the CXCR4-driven migration of $\mathrm{CD}^{+} 4^{+}$cells from $\mathrm{mPB}$ and
$\mathrm{CB}$. This effect was more prominent when $\mathrm{mPB}$ cells were assayed.

3.4. CD34 ${ }^{+}$Cells from $m P B$ Show Increased Clonogenic Ability after In Vitro Migration toward Selected Combinations of Proinflammmatory Cytokines. Cell migration could be considered a selection of cells with different function and properties; for this reason, we tested the clonogenic potential of migrated $\mathrm{CB}$ and $\mathrm{mPB} \mathrm{CD} 34^{+}$cells (Figure 2 and Supplementary Table 4).

Of note, at variance with the results of freshly isolated cells (Figure 2) in terms of clonogenic output, CXCL12 + IL- $6+$ TNF- $\alpha \quad(p \leq 0.001) \pm \operatorname{IL} 1 \beta \quad(p \leq 0.01) \pm$ TIMP- $1 \quad(p \leq$ 0.01 ) selected a subset of $\mathrm{CD} 34^{+}$cells from $\mathrm{mPB}$ with higher clonogenic potential as compared with CXCL12 alone (Figure 4(a). By contrast, no effects were found in the CB-derived counterparts (Figures 4(a) and 4(b)). Comparing the two sources, only the $\mathrm{mPB}$-derived $\mathrm{CD} 34^{+}$cells migrated toward CXCL12 + IL- $6+$ TNF- $\alpha$ increased the CFU-C output ( $p \leq 0.05$ ) (Figures $4(\mathrm{a})$ and $4(\mathrm{~b})$ ). We then analyzed separately CFU-GM (Figures $4(\mathrm{c})$ and $4(\mathrm{~d})$ ) and BFU-E (Figures 4(e) and 4(f)) growth, observing a significant promotion of the CFU-GM growth in $\mathrm{mPB}$ CD $34^{+}$ cells after migration toward CXCL12 + IL- $6+$ TNF- $\alpha$ and CXCL1 $2+$ IL- $6+$ IL- $1 \beta+$ TNF- $\alpha \pm$ TIMP- 1 as compared to CXCL12 alone ( $p \leq 0.01, p \leq 0.05$ and $p \leq 0.01$, resp.). Comparing the two sources, CFU-GM growth was higher after migration of $\mathrm{mPB} \mathrm{CD}_{3} 4^{+}$cells toward CXCL12+IL-6 + TNF- $\alpha(p \leq 0.01)$ (Figure 4(c)). With regard the erythroid progenitors, no significant differences in BFU-E growth were observed between treated and untreated cells of either $\mathrm{CB}$ or $\mathrm{mPB}$, with exception of the migrated $\mathrm{mPB}$-derived $\mathrm{CD}_{4}{ }^{+}$cells towards CXCL12 + all cytokines $(p \leq 0.05$; Figures $4(\mathrm{e})$ and $4(\mathrm{f}))$. Comparing the two sources, $\mathrm{mPB}$ $\mathrm{CD} 34^{+}$cells showed higher clonogenic ability $(p \leq 0.05)$ after migration toward CXCL12 + IL- $6+$ TNF- $\alpha$. When colony composition was analyzed (Figure S4), combined inflammatory factors do not significantly modify the CFU-GM/ BFU-E proportion of migrated CD $34^{+}$cells of both sources.

Overall, here we demonstrate that selected combinations of proinflammatory cytokines promoted the CXCR4-driven migration of $\mathrm{mPB}$-derived $\mathrm{CD} 34^{+}$cells with higher clonogenic ability and granulomonocytic potential.

3.5. The Copresence of BMSCs and Combined Inflammatory Cytokines Does Not Show Additive/Synergistic Effect in Terms of Hemopoietic Supportive Role. To mimic the in vivo niche and to investigate the role of normal BMSCs in the inflammation-driven functional behavior of normal HSPCs, we cocultured CB- or mPB-derived CD $34^{+}$cells with BMSCs from HD in the presence or absence of combined proinflammatory cytokines.

As shown in Figure 5(a), the survival of $\mathrm{CD} 34^{+}$cells, either from $\mathrm{CB}$ or $\mathrm{mPB}$, was significantly promoted by BMSCs ( $p \leq 0.01$ and $p \leq 0.05$, resp.). Interestingly, cocultures with BMSCs decreased the percentage of apoptotic CB $\mathrm{CD} 34^{+}$cells compared with the monoculture counterparts, with $33.5 \pm 8.8 \%$ of apoptosis in cocultures versus 76.71 $\pm 8.9 \%$ in monocultures ( $p \leq 0.05$, data not shown). Similar 


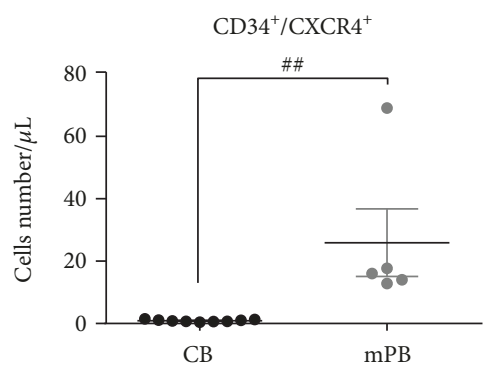

(a)

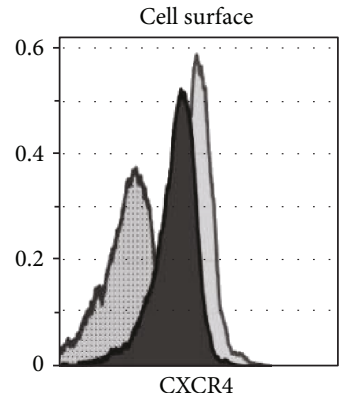

CB-CD34+ $\square$ mPB-CD34+

Isotype control

(b)

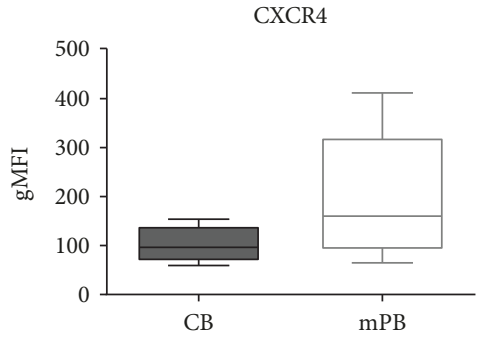

(c)

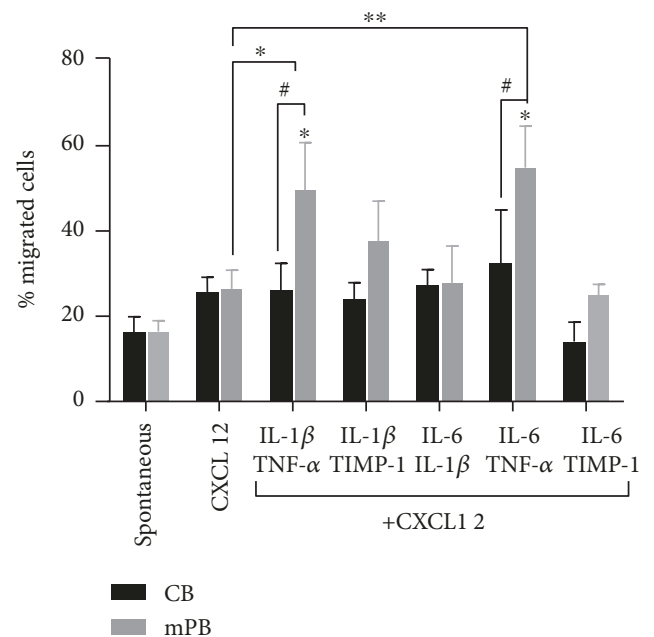

(d)

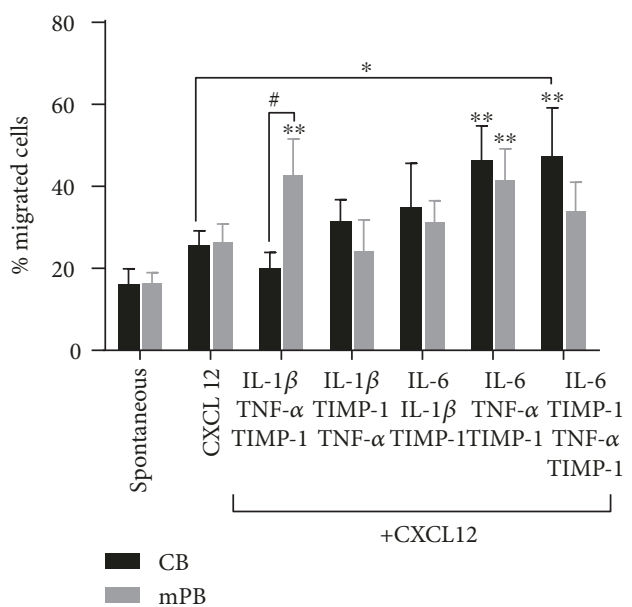

(e)

Figure 3: Migratory response of CB- and mPB-derived CD34 ${ }^{+}$cells in the presence of combined inflammatory stimuli. (a) The absolute number of circulating $\mathrm{CD} 34^{+}$cells from $\mathrm{CB}$ unit $(n=9)$ or $\mathrm{mPB}(n=5)$ and coexpressing the CXCR4 receptor are shown. (b) Representative histogram of CXCR4 expression in $\mathrm{CB}$ - and $\mathrm{mPB}$-derived CD34 ${ }^{+}$cells compared to isotype control. (c) Geometric mean value of CXCR4-positive cells on the $\mathrm{CD} 34^{+}$population after isolation from $\mathrm{CB}(n=5)$ and $\mathrm{mPB}(n=5)$ units. (d) Migration assay using transwell after o/n spontaneous migration (control) or exposure to CXCL12 $(120 \mathrm{ng} / \mathrm{mL})$ or to two-by-two inflammatory cytokines plus CXCL12 as chemoattractants. Percentages of migrated CD34 ${ }^{+}$cells from CB (black columns, $n=4$ ) or mPB (grey columns, $\left.n=4\right)$ are shown. (e) Migration assay using transwell after o/n spontaneous migration (control) or exposure to CXCL12 (120 ng/mL) or to CXCL12 plus multiple inflammatory cytokines as chemoattractants. Percentages of migrated CD34 ${ }^{+}$cells from CB (black columns, $n=4$ ) or $\mathrm{mPB}$ (grey columns, $n=4$ ) are shown. Data are presented as mean $\pm \mathrm{SEM}$ of $n$ (as above described) independent experiments $\left({ }^{*} p \leq 0.05\right.$ and ${ }^{* *} p \leq 0.01$ versus untreated cells (control) or CXCL12 alone) ( ${ }^{\#} p \leq 0.05$ and ${ }^{\# \#} p \leq 0.01 \mathrm{CB}$ versus mPB).

results were obtained when cocultures of $\mathrm{mPB} \mathrm{CD} 34^{+}$cells were performed, with $48.63 \pm 2.1 \%$ of apoptosis in cocultures versus $78.92 \pm 6.05 \%$ in monocultures $(p \leq 0.05)$ (data not shown). However, in the presence of BMSCs (Figures 5(b) and 5(c)), the viability of cocultured $\mathrm{CD}_{3}{ }^{+}$cells from $\mathrm{CB}$ or $\mathrm{mPB}$ was not significantly modified by the combined inflammatory factors as compared with the untreated counterparts. Comparing the two sources, only IL-6 + TIMP$1(p \leq 0.01)$ significantly increased the number of viable cocultured CB-derived CD $34^{+}$cells.

Altogether, these findings demonstrate that (1) the survival of normal $\mathrm{CD}_{3} 4^{+}$cells is highly promoted by normal BMSCs through a strong protection from apoptosis, (2) BMSCs alone or the combined proinflammatory cytokines stimulate the survival of normal HSPCs at the same extent, and (3) the copresence of BMSCs and the combined inflammatory cytokines does not show additive/synergistic effect in terms of hemopoietic supportive role.

3.6. Proinflammatory Cytokines Do Not Modify the In Vitro Migration of $\mathrm{CD}_{3} 4^{+}$Cells from $\mathrm{CB}$ and $\mathrm{mPB}$ toward BMSCs. The BMSCs produce CXCL12 as mediator of migratory response of different cell types. CXCL12 is constitutively expressed by murine and human BM stromal cells [29]. To explore the effects of inflammation on the CXCR4-driven migratory ability of $\mathrm{CD} 34^{+}$cells in the presence or absence of BMSCs, we set up a migratory assay towards CXCL12 alone and BMSCs alone or in combination with various inflammatory cytokines. Of note, in order to mimic the 
CFU-C

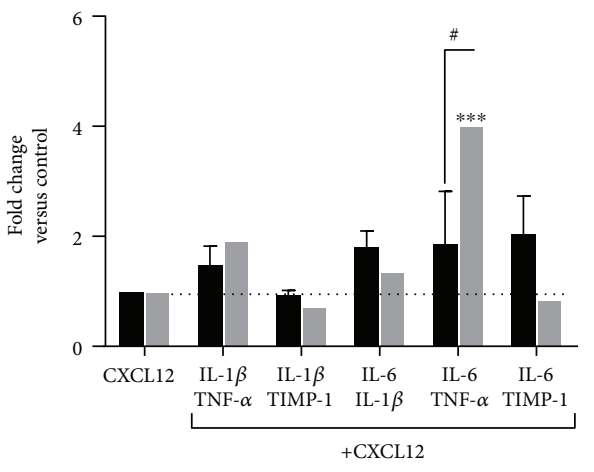

$\mathrm{CB}$

$\mathrm{mPB}$

(a)

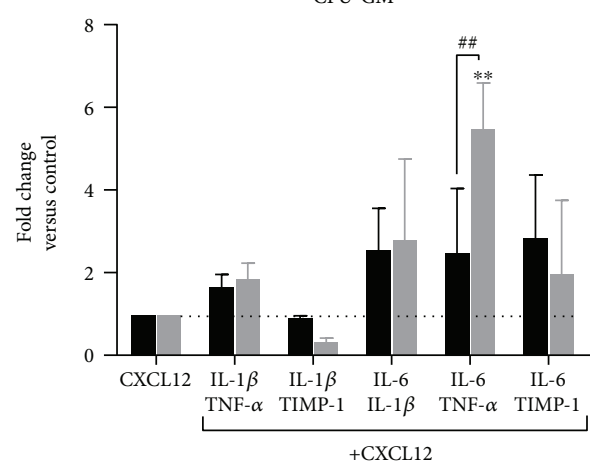

- $\mathrm{CB}$

$\mathrm{mPB}$

(c)

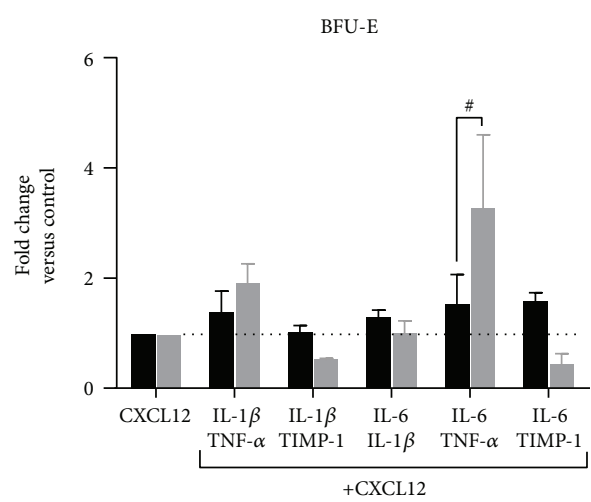

- $\mathrm{CB}$

$\mathrm{mPB}$

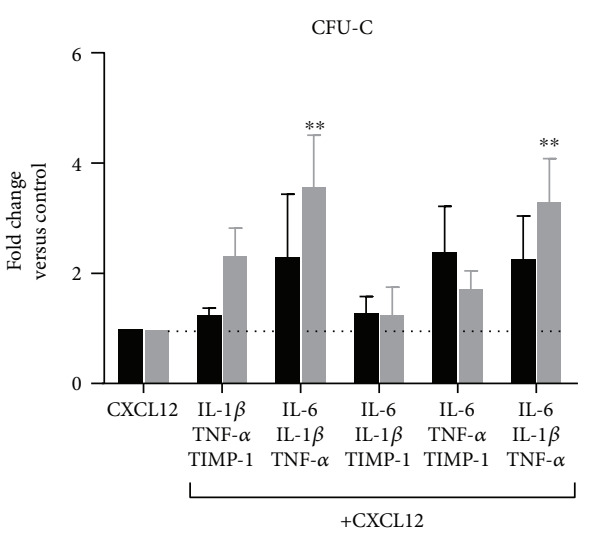

- $\mathrm{CB}$

$\mathrm{mPB}$

(b)

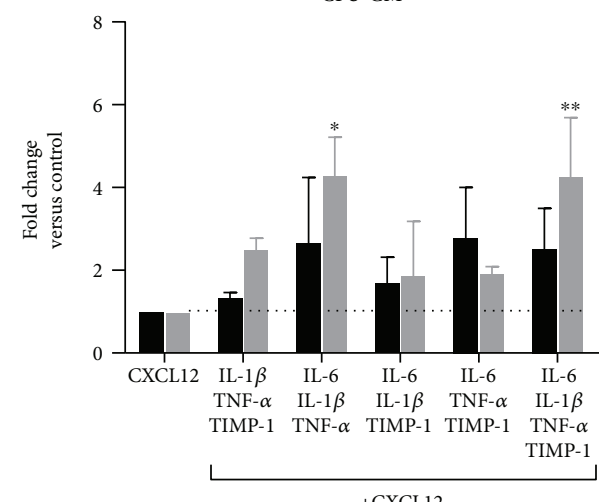

- $\mathrm{CB}$

$\mathrm{mPB}$

(d)

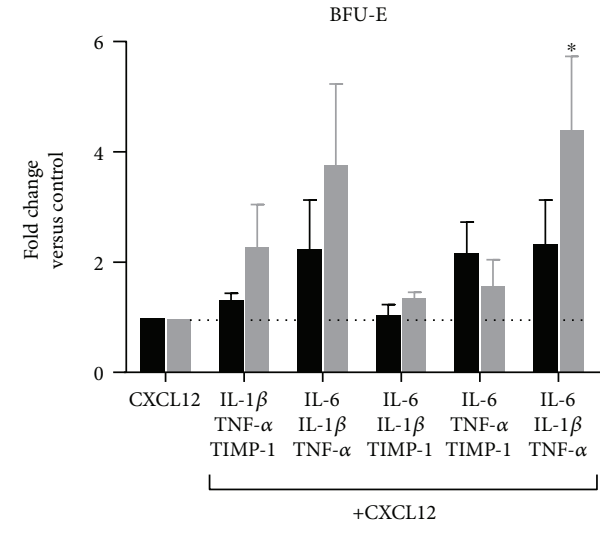

- $\mathrm{CB}$

- $\mathrm{mPB}$

(e)

(f)

Figure 4: Clonogenic output of CB- or mPB-derived CD $34^{+}$cells after migration toward different combinations of inflammatory cytokines plus CXCL12. Panels a and b show the fold change of clonogenic potential of CB-derived $(n=4-8$ independent experiments) and mPB-derived CD34 ${ }^{+}$cells ( $n=4-9$ independent experiments) after migration toward CXCL12 with or without the two-by-two combination (a) or multiple (b) combinations of proinflammatory factors (postmigration CFU-C). (c-d) Fold change of CFU-GM (c-d) and BFU-E (e-f) growth after migration towards CXCL12 in the presence of various combinations of cytokines. Dot lines were used to mark control samples after migration towards CXCL12. Results are expressed as mean fold change of CFU $-\mathrm{C} \pm \operatorname{SEM}\left({ }^{*} p \leq 0.05,{ }^{* *} p \leq 0.01\right.$, and ${ }^{* * *} p \leq 0.001$; versus control cells (CXCL12)) ( ${ }^{\#} p \leq 0.05$ and ${ }^{\# \#} p \leq 0.01 \mathrm{CB}$ versus $\left.\mathrm{mPB}\right)$. 


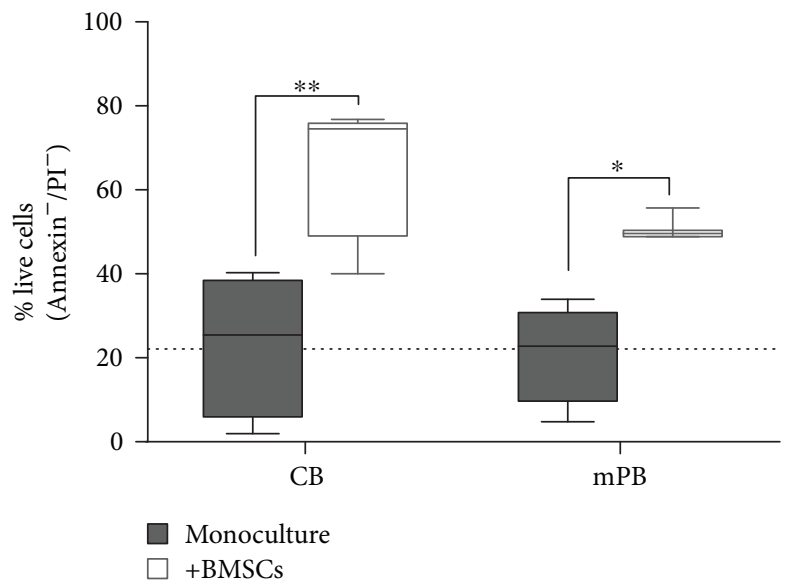

(a)

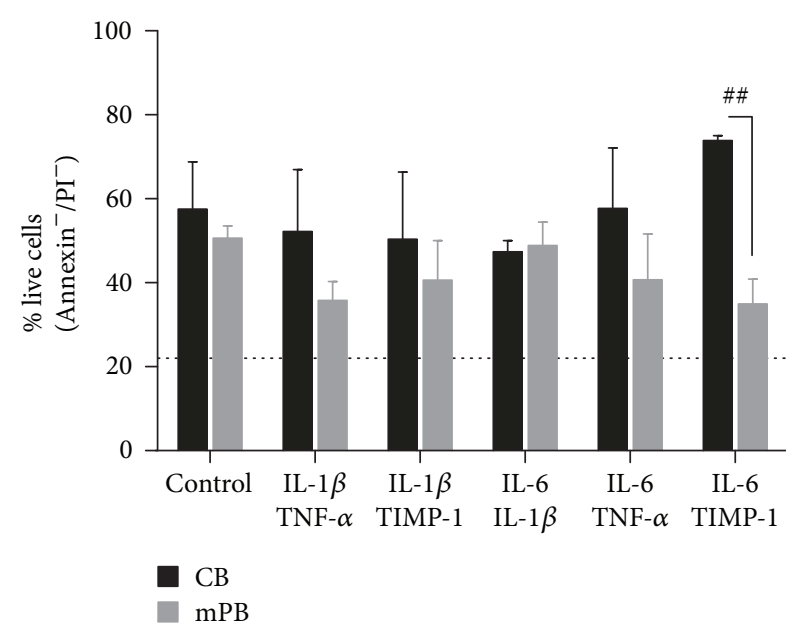

(b)

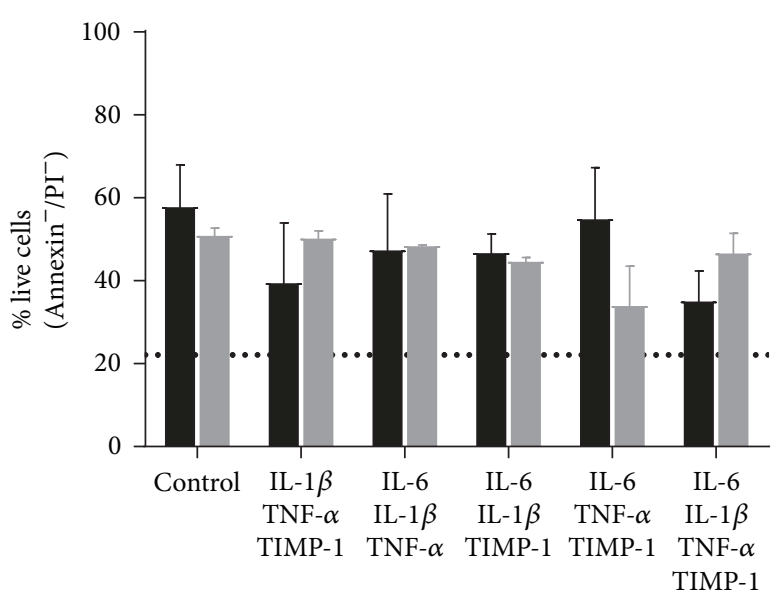

(c)

Figure 5: Survival of CB- and mPB-derived $\mathrm{CD} 34^{+}$cells after cocultures with HD-BMSCs and in the presence or the absence of combined inflammatory cytokines. (a) Comparison between 24-hour monocultures and cocultures of CB and mPB-derived CD34 cells ( $n=4$ independent experiments, resp.) with BMSCs for in vitro survival (Annexin V/PI staining) is shown. Percentages of live $\mathrm{CB}$ - or $\mathrm{mPB}-\mathrm{CD} 34^{+}$cells in the presence of BMSCs and/or proinflammatory cytokines with two by two combination (b) or multiple combinations (c) in comparison to $\mathrm{CD} 34^{+}$cells cocultured with BMSCs but without inflammatory stimuli are shown. For each graph, to highlight the comparison with cocultures, a dot line represented the mean percentage of live cells in all monocultures (CB and $\mathrm{mPB} \mathrm{CD} 34^{+}$cells) $\left({ }^{*} p \leq 0.05\right.$ and ${ }^{* *} p \leq 0.01$ versus control cells) $\left({ }^{\#} p \leq 0.01 \mathrm{CB}\right.$ vs $\left.\mathrm{mPB}\right)$.

in vivo pattern, along with inflammatory cytokines, a suboptimal concentration of CXCL12 $(120 \mathrm{ng} / \mathrm{mL})$ was also added.

As shown in Figure 6(a), we compared the spontaneous migration of $\mathrm{CD} 34^{+}$cells from $\mathrm{CB}$ and $\mathrm{mPB}$ with the migration towards BMSCs seeded on the bottom of the transwell system, as chemoattractant. We found that the migration of $\mathrm{CD} 34^{+}$cells from both sources was promoted by BMSCs, being significant $(p \leq 0.05)$ with $\mathrm{CB}$ only. However, the migration rate of $\mathrm{CB}$ or $\mathrm{mPB} \mathrm{CD} 34^{+}$cells was not increased by the presence of CXCL12 + BMSCs as compared with that of CXCL12 alone or BMSCs alone (Figures 6(b) and 6(c)). When we added various combinations of proinflammatory cytokines in the presence of CXCL12 and BMSCs, once again we did not find any significant difference in the migration rate of $\mathrm{CD} 34^{+}$cells between treated and untreated cells or between the two sources (Figures 6(b) and 6(c)).
These experiments demonstrate that the BMSCs exert a potent chemoattractive effect on normal HSPCs; moreover, in the presence of BMSCs, these combined proinflammatory factors are unable to significantly modify the CXCR-4-driven migratory behavior of HSPCs from both sources.

\section{Discussion}

Several cytokine-based strategies enhancing hemopoiesis, homing, and subsequent engraftment of $\mathrm{CB} / \mathrm{mPB}$-derived HSCs have been previously described [30]. However, critical steps are involved in these processes and further insights are necessary to better understand HSPCs homing and engraftment [31]. Along with a role as activators of immune cell function, a growing evidence now demonstrates that proinflammatory cytokines strongly affect the size and 


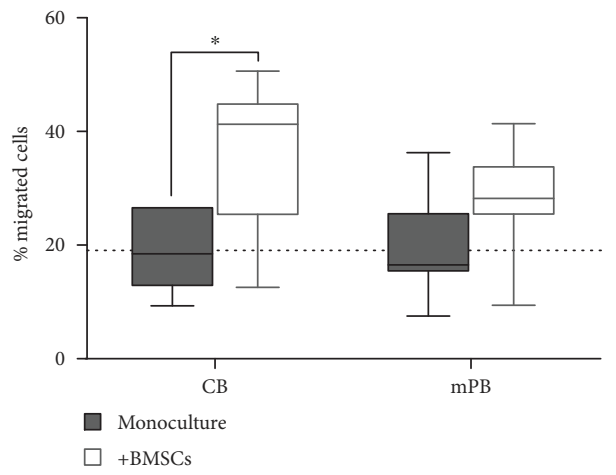

(a)

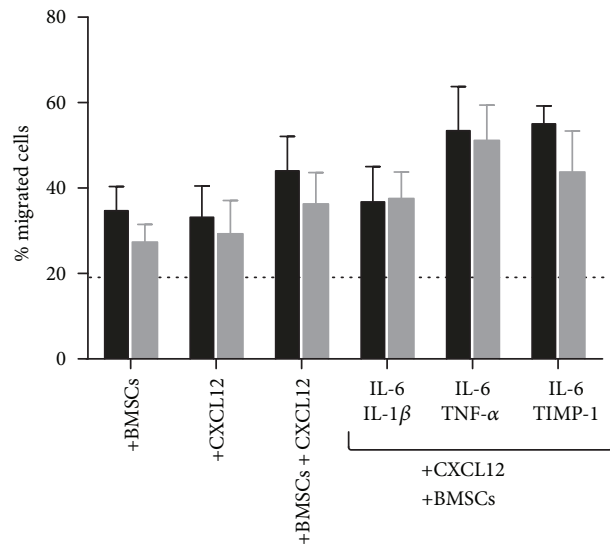

- $\mathrm{CB}$

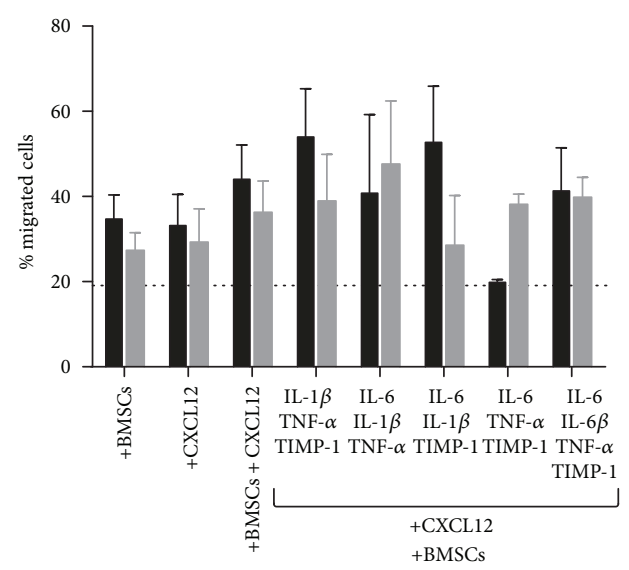

(c)

Figure 6: Migration of CB- and mPB-derived CD34 ${ }^{+}$cells towards CXCL12 and combined proinflammatory stimuli gradient and in the presence of normal BMSCs as further chemoattractant. (a) Comparison between spontaneous migration and migration toward BMSCs precultured on the bottom for 24 hours before seeding CD $34^{+}$cells on the top of the transwell system $(n=4$ independent experiments, resp.). Percentages of migrated $\mathrm{CD}_{3} 4^{+}$cells (seeded on the top of transwell) towards BMSCs (seeded 24 hours before on the bottom) plus CXCL12 and proinflammatory cytokines (two-by-two combination (b) or multiple combinations (c)) as chemoattractants are shown. For each graph, to highlight the comparison with cocultures, a dot line represented the mean percentage of migrated cells towards CXCL12 in all monocultures (CB and $\mathrm{mPB} \mathrm{CD} 34^{+}$cells) $\left({ }^{*} p \leq 0.05\right.$ versus control cells).

lineage distribution of the blood cells via reprogramming of HSC/HSPC and the supporting BM niche [5, 32]. Along with the cytokine storm, the network created by dangerassociated molecular patterns (PAMPs/DAMPs) and alarmins could deviate HSCs fate, directly or indirectly via stromal cells [33]. Based on these evidences and due to the lack of informative data, it is of utmost importance to clarify the impact of proinflammatory cytokines on the biology of the normal HSPC and its BM microenvironment. A better understanding of the mechanisms driven by the inflammatory milieu in HSPCs may lead to better transplantation outcomes and knowledge of hematological defects or malignancies.

Here we tested various combinations of proinflammatory cytokines such as IL- $1 \beta$, IL- 6 , TNF- $\alpha$, and TIMP- 1 in order to investigate their functional role on the in vitro behavior of young (CB-derived) and adult (mPB-derived) $\mathrm{CD} 34^{+}$cells. To mirror the in vivo condition, tested cytokines were two to two or multiple combined. We selected these inflammatory cytokines for the following features: (i) IL-6 is a pleiotropic proinflammatory cytokine that acts on many cell types including hemopoietic cells. It has been implicated as a critical activator of myelopoiesis in response to pathogen infection and chronic inflammation [34]; (ii) IL- $1 \beta$ is a potent inflammatory cytokine that mediates leukocytosis and thrombocytosis under inflammatory conditions by inducing various cytokines (i.e., granulocyte colony-stimulating factor and IL-6) [7]. Moreover, Pietras et al. [35] recently demonstrated that while IL- $1 \beta$ is dispensable for steady-state hemopoiesis, acute exposure to IL- $1 \beta$ accelerates HSC proliferation and instructs HSC priming for a myeloid fate. Lastly, it is involved in the pathogenesis of solid tumors and hematological malignancies [36]; (iii) TNF- $\alpha$ negatively regulates the expansion and self-renewal of HSPCs [37]. However, other evidence suggests that TNF signalling may enhance HSC function [38, 39]; (iiii) TIMP-1, through receptor (CD63) binding, has a role in multiple biological processes, including inflammation and immune regulation. We recently demonstrated that it displays cytokine-like features in the normal and leukemic HSPC compartment $[25,26]$. 
In addition, experimental evidence demonstrated that combined proinflammatory cytokines such as IL- 6 and TNF- $\alpha$ are critical for both inflammation and cancer by activating STAT3 and the NF- $\kappa$ B complex [40]. Furthermore, other inflammatory cytokines and pathways (such as IL-6) are induced by IL-1 $\beta$ and are involved in malignancy [36]. Thus, the combined action of these cytokines could constitute a central signalling pathway that promotes inflammation and tumor growth.

Comparing the two sources (neonatal versus adult) of HSPCs, here we demonstrated that the following:

(1) Various combinations of inflammatory cytokines mainly enhance the in vitro survival of $\mathrm{CB}$-derived CD $34^{+}$cells.

(2) As compared to $\mathrm{CB}, \mathrm{mPB}$-derived $\mathrm{CD} 34^{+}$cells are susceptible to selected combinations of inflammatory factors in terms of proliferation and hemopoietic function.

(3) TNF- $\alpha$, alone or in combination, promotes the expression of the CD13 myeloid marker and CD44, an adhesion/proliferation marker of normal and leukemic cells.

(4) Along with an increased number of circulating $\mathrm{CXCR}^{+} \mathrm{CD} 34^{+}$cells, selected combinations of inflammatory cytokines mainly enhance the in vitro migration of $\mathrm{mPB}$-derived $\mathrm{CD} 34^{+}$cells.

(5) BMSCs alone or combined inflammatory cytokines promote survival/migration of HSPCs from both sources at the same extent; moreover, their copresence does not show additive/synergistic effect in terms of hemopoietic supportive role.

Of note, despite that the use of frozen/thawed CD $34^{+}$ cells in some cases might have influenced the variability of phenotype/clonogenic ability, our results clearly demonstrate that the selected network of proinflammatory factors has the potential to activate either neonatal or adult normal hemopoiesis and acts as regulator of HSPCs. Moreover, these results are consistent with previously described promoting effects of the inflammatory microenvironment on hemopoiesis $[4,7,12$,$] . Taking into account that the functional conse-$ quences of inflammation-related molecules depend on the duration of exposure (acute versus chronic), our results may provide a starting point to investigate whether the inflammatory cues contribute to creating a favorable milieu for the development of hematological malignancies through hemopoietic activation.

Several groups evaluated the expression of hematopoietic markers, identifying various subpopulations of $\mathrm{CD}_{3} 4^{+}$cells in $\mathrm{CB}$ or $\mathrm{mPB}$ samples $[41,42]$. Interestingly, we found that, when $\mathrm{CB}$ - or $\mathrm{mPB}$-derived $\mathrm{CD} 34^{+}$cells were treated with combined proinflammatory cytokines including TNF- $\alpha$, CD13 expression was highly promoted. The CD13/aminopeptidase $\mathrm{N}$ is expressed on various cell types, including myeloid hematopoietic cells, and regulates biological phenomena such as differentiation, proliferation, apoptosis, motility, and tumor cell invasion. Importantly, CD13 degrades the chemokine CXCL11 and modulates CXCL12-induced migration $[43,44]$. It has also been reported that high levels of human CD13 correlate with leukemic cell resistance to apoptosis [45]. Moreover, CD13 is differentially expressed in discrete states of differentiation of neoplastic myeloid cells [46]. Along with CD13, here we found modulation of the homingassociated cell adhesion molecule CD44. Recently, CD44, as a receptor for hyaluronan, emerges as mediator of cell-cell and cell-matrix interactions and as pivotal trigger in cancer stem cell communication with their microenvironment [47, 48]. Here we identified combined proinflammatory cytokines including TNF- $\alpha$, which are able to upregulate CD44 expression on the surface of normal CD $34^{+}$cells. Although TNF- $\alpha$ driven modulation of CD44 expression was already reported in several cancers [49], this is the first time that a strong link has been found between combined inflammatory cytokines and CD44 expression on HSPCs. Therefore, our results clearly indicate that the inflammation-driven CD13 and CD44 upregulation on neonatal or adult CD $34^{+}$cells has the potential of modulating key functional pathways (i.e., survival/differentiation) of the normal hemopoietic progenitor cells. Interestingly, these pathways may also play a role in myeloproliferation and leukemogenesis.

Several studies have shown that HSC can be expanded in cytokine-driven culture and by MSC feed layers [50, 51]. Consistently, our data clearly showed that normal BMSCs enhance survival and migration of $\mathrm{CB}$ - and $\mathrm{mPB}$-derived $\mathrm{CD}_{3}{ }^{+}$cells. Due to their capacity to modulate oxidative stress, it is likely that BMSCs are capable of inhibiting apoptosis; moreover, producing CXCL12 [52], they enhance cell migration. Interestingly, even though it is likely that different mechanisms are involved, the BMSC-driven promoting effect of the CB-derived $\mathrm{CD}_{3} 4^{+}$cell survival is similar to that induced by the combined inflammatory cytokines. A similar trend was observed in $\mathrm{mPB}$. However, for the first time, we investigated the copresence of BMSCs and various combinations of selected proinflammatory cytokines. Surprisingly, the copresence of inflammatory stimuli with BMSCs did not significantly modify the survival-migration rate of normal HSPCs as compared with that observed after stimulation with BMSCs alone or combined inflammatory cytokines alone. Of note, the BMSCs are capable to sustain the survival of $\mathrm{mPB}$-derived $\mathrm{CD} 34^{+}$cells in the presence of IL$1 \beta+$ TIMP-1. These findings demonstrate that in our culture system an acute inflammatory stimulus does not impair the hemopoietic-supportive role of BMSCs. Interestingly, based on murine models, it has been previously demonstrated that MSCs can modulate inflammation by secreting soluble receptors for IL- 1 and TNF, which bind to IL- 1 and TNF- $\alpha$ and neutralize the activity of the cytokines [53-55]. We can therefore hypothesize that in our cocultures the promotion of normal HSPCs survival/migration is mainly due to BMSCs which show regulatory properties of the hemopoietic function of HSPCs because they are capable of balancing the proinflammatory signal-driven hemopoietic activation. These results suggest that exploiting or modulating the thin balance between pro- and anti-inflammatory pathways may be a clinically relevant approach in hematological malignancies. 


\section{Conclusion}

The goal of this study is the demonstration that an inflammatory microenvironment promotes distinct in vitro functional activation of neonatal and adult HSPCs and that an acute inflammatory stress does not impair the hemopoietic promoting effect of BMSCs. Moreover, this study may represent a starting point for future studies aiming at addressing the role of inflammation and the balance with antiinflammatory signals in the functional behavior of normal HSPCs and their transformation to a leukemic phenotype.

\section{Data Availability}

The data used to support the findings of this study are available from the corresponding author upon request.

\section{Disclosure}

An earlier version of this work has been presented at XIV Congress of the Italian Society of Experimental Hematology, Rimini, Italy, 2016.

\section{Conflicts of Interest}

No potential conflicts of interest were disclosed.

\section{Authors' Contributions}

The following are the contributions of the authors in this study: Dorian Forte, Daria Sollazzo, and Martina Barone: conception/design, collection and assembly of data, data analysis and interpretation, manuscript writing, and final approval of manuscript; Marisole Allegri, Angela di Martella Orsi, and Giuseppe Auteri: collection and assembly of data and final approval of manuscript; and Lucia Catani, Francesca Palandri, Marco Romano, Nicola Vianelli, and Michele Cavo: provision of study material, data analysis and interpretation, manuscript writing, and final approval of manuscript. Francesca Palandri and Lucia Catani contributed equally to this work.

\section{Acknowledgments}

This work was funded by Associazione Italiana Contro le Leucemie-Bologna section (BolognAIL) and by the University of Bologna (RFO 2015-2016 to Lucia Catani). Daria Sollazzo and Martina Barone were supported by the University of Bologna. Dorian Forte was supported by the University of Bologna and BolognAIL, and he is a recipient of the Italian Association for Cancer Research (AIRC) Fellowships for Abroad. The British Heart Foundation supported Marco Romano (Grant no. TG/16/2/32657).

\section{Supplementary Materials}

Supplementary Figure 1: survival of $\mathrm{CD} 34^{+}$cells derived from $\mathrm{CB}$ or $\mathrm{mPB}$ in the presence of 517 proinflammatory cytokines alone. Supplementary Figure 2: phenotype of $\mathrm{CD} 34^{+}$cells derived from $\mathrm{CB}$ or $\mathrm{mPB}$ in the presence of proinflammatory cytokines alone. Supplementary Figure 3: colony composition in the presence or absence of 521 combined inflammatory cytokines. Supplementary Figure 4: colony composition of CB- and $\mathrm{mPB}$-derived $\mathrm{CD} 34^{+}$cells after migration toward CXCL12 alone and CXCL12 plus various combinations of inflammatory factors. Supplementary Table 1: antibodies used to characterize the $\mathrm{CD} 34^{+}$cells. Supplementary Table 2: absolute numbers of gMFI for CD13 and $\mathrm{CD} 44$ expression in $\mathrm{CD} 34^{+}$cells from $\mathrm{CB}$ or $\mathrm{mPB}$ after incubation for 24 hours in the presence/absence of 528 inflammatory stimuli. Supplementary Table 3: absolute numbers of CFU-C, CFU-GM, and BFU-E after incubation of CD34 ${ }^{+}$ cells from $\mathrm{CB}$ or $\mathrm{mPB}$ in methylcellulose-based medium for 14 days in the presence/absence of inflammatory stimuli. Supplementary Table 4: absolute numbers of CFU-C, GM$\mathrm{CFU}$, and BFU-E in $\mathrm{CD} 34^{+}$derived from $\mathrm{CB}$ or $\mathrm{mPB}$ counted after migration towards inflammatory stimuli and seeded in methylcellulose-based medium for 14 days. (Supplementary Materials)

\section{References}

[1] M. T. Baldridge, K. Y. King, N. C. Boles, D. C. Weksberg, and M. A. Goodell, "Quiescent haematopoietic stem cells are activated by IFN- $\gamma$ in response to chronic infection," Nature, vol. 465, no. 7299, pp. 793-797, 2010.

[2] M. A. G. Essers, S. Offner, W. E. Blanco-Bose et al., "IFN $\alpha$ activates dormant haematopoietic stem cells in vivo," Nature, vol. 458, no. 7240, pp. 904-908, 2009.

[3] A. Mantovani, P. Allavena, A. Sica, and F. Balkwill, "Cancerrelated inflammation," Nature, vol. 454, no. 7203, pp. 436444, 2008.

[4] C. Mirantes, E. Passegué, and E. M. Pietras, "Pro-inflammatory cytokines: emerging players regulating HSC function in normal and diseased hematopoiesis," Experimental Cell Research, vol. 329, no. 2, pp. 248-254, 2014.

[5] E. M. Pietras, "Inflammation: a key regulator of hematopoietic stem cell fate in health and disease," Blood, vol. 130, no. 15, pp. 1693-1698, 2017.

[6] Q. He and F. Liu, "Unexpected role of inflammatory signaling in hematopoietic stem cell development: its role beyond inflammation," Current Opinion in Hematology, vol. 23, no. 1, pp. 18-22, 2016.

[7] S. Hemmati, T. Haque, and K. Gritsman, "Inflammatory signaling pathways in preleukemic and leukemic stem cells," Frontiers in Oncology, vol. 7, 2017.

[8] M. E. Bernardo and W. E. Fibbe, "Mesenchymal stromal cells: sensors and switchers of inflammation," Cell Stem Cell, vol. 13, no. 4, pp. 392-402, 2013.

[9] M. J. Regulski, "Mesenchymal stem cells: "guardians of inflammation"," Wounds, vol. 29, no. 1, pp. 20-27, 2017.

[10] D. Trivanović, J. Krstić, I. O. Djordjević et al., “The roles of mesenchymal stromal/stem cells in tumor microenvironment associated with inflammation," Mediators of Inflammation, vol. 2016, Article ID 7314016, 14 pages, 2016.

[11] D. J. Prockop and J. Youn Oh, "Mesenchymal stem/stromal cells (MSCs): role as guardians of inflammation," Molecular Therapy, vol. 20, no. 1, pp. 14-20, 2012.

[12] H. C. Hasselbalch, "Perspectives on chronic inflammation in essential thrombocythemia, polycythemia vera, and 
myelofibrosis: is chronic inflammation a trigger and driver of clonal evolution and development of accelerated atherosclerosis and second cancer?," Blood, vol. 119, no. 14, pp. 3219-3225, 2012.

[13] M. K. Juric, S. Ghimire, J. Ogonek et al., "Milestones of hematopoietic stem cell transplantation - from first human studies to current developments," Frontiers in Immunology, vol. 7, p. $470,2016$.

[14] C. Voermans, W. R. Gerritsen, A. E. G. K. von dem Borne, and C. E. van der Schoot, "Increased migration of cord bloodderived CD34+ cells, as compared to bone marrow and mobilized peripheral blood CD34+ cells across uncoated or fibronectin-coated filters," Experimental Hematology, vol. 27, no. 12, pp. 1806-1814, 1999.

[15] F. Moretta, F. Petronelli, B. Lucarelli et al., "The generation of human innate lymphoid cells is influenced by the source of hematopoietic stem cells and by the use of G-CSF," European Journal of Immunology, vol. 46, no. 5, pp. 1271-1278, 2016.

[16] J. Kellner, S. Li, P. A. Zweidler-McKay, E. J. Shpall, and I. McNiece, "Phenotypic and functional comparison of mobilized peripheral blood versus umbilical cord blood megakaryocyte populations," Cytotherapy, vol. 17, no. 4, pp. 418-427, 2015.

[17] C. D. Bruyn, A. Delforge, P. Martiat, and D. Bron, "Ex vivo expansion of megakaryocyte progenitor cells: cord blood versus mobilized peripheral blood," Stem Cells and Development, vol. 14, no. 4, pp. 415-424, 2005.

[18] F. Bracho, C. van de Ven, E. Areman et al., "A comparison of ex vivo expanded DCs derived from cord blood and mobilized adult peripheral blood plastic-adherent mononuclear cells: decreased alloreactivity of cord blood DCs," Cytotherapy, vol. 5, no. 5, pp. 349-361, 2003.

[19] H. Jin, H.-S. Kim, S. Kim, and H. O. Kim, "Erythropoietic potential of $\mathrm{CD} 34+$ hematopoietic stem cells from human cord blood and G-CSF-mobilized peripheral blood," BioMed Research International, vol. 2014, Article ID 435215, 9 pages, 2014.

[20] D. Sollazzo, D. Forte, N. Polverelli et al., "Crucial factors of the inflammatory microenvironment (IL- $1 \beta /$ TNF- $\alpha /$ TIMP-1) promote the maintenance of the malignant hemopoietic clone of myelofibrosis: an in vitro study," Oncotarget, vol. 7, no. 28, pp. 43974-43988, 2016.

[21] K. Mizrahi, J. Stein, I. Yaniv, O. Kaplan, and N. Askenasy, "TNF- $\alpha$ has tropic rather than apoptotic activity in human hematopoietic progenitors: involvement of TNF receptor-1 and caspase-8," Stem Cells, vol. 31, no. 1, pp. 156-166, 2013.

[22] H. E. Broxmeyer, D. E. Williams, L. Lu et al., "The suppressive influences of human tumor necrosis factors on bone marrow hematopoietic progenitor cells from normal donors and patients with leukemia: synergism of tumor necrosis factor and interferon-gamma," The Journal of Immunology, vol. 136, no. 12, pp. 4487-4495, 1986.

[23] I. Dybedal, D. Bryder, A. Fossum, L. S. Rusten, and S. E. Jacobsen, "Tumor necrosis factor (TNF)-mediated activation of the p 55 TNF receptor negatively regulates maintenance of cycling reconstituting human hematopoietic stem cells," Blood, vol. 98, no. 6, pp. 1782-1791, 2001.

[24] S. Boettcher and M. G. Manz, "Regulation of inflammationand infection-driven hematopoiesis," Trends in Immunology, vol. 38, no. 5, pp. 345-357, 2017.

[25] L. Rossi, D. Forte, G. Migliardi et al., "The tissue inhibitor of metalloproteinases 1 increases the clonogenic efficiency of human hematopoietic progenitor cells through CD63/PI3K/ Akt signaling," Experimental Hematology, vol. 43, no. 11, pp. 974-985.e1, 2015.

[26] D. Forte, V. Salvestrini, G. Corradi et al., "The tissue inhibitor of metalloproteinases-1 (TIMP-1) promotes survival and migration of acute myeloid leukemia cells through CD63/ PI3K/Akt/p 21 signaling," Oncotarget, vol. 8, no. 2, pp. 22612274, 2017.

[27] C. M. Wilk, F. A. Schildberg, M. A. Lauterbach et al., "The tissue inhibitor of metalloproteinases-1 improves migration and adhesion of hematopoietic stem and progenitor cells," Experimental Hematology, vol. 41, no. 9, pp. 823-831.e2, 2013.

[28] T. Lapidot and I. Petit, "Current understanding of stem cell mobilization: the roles of chemokines, proteolytic enzymes, adhesion molecules, cytokines, and stromal cells," Experimental Hematology, vol. 30, no. 9, pp. 973-981, 2002.

[29] K. Golan, O. Kollet, and T. Lapidot, "Dynamic cross talk between S1P and CXCL12 regulates hematopoietic stem cells migration, development and bone remodeling," Pharmaceuticals, vol. 6, no. 9, pp. 1145-1169, 2013.

[30] M. A. Gertz, "Current status of stem cell mobilization," British Journal of Haematology, vol. 150, no. 6, pp. 647-662, 2010.

[31] M. Z. Ratajczak and M. Suszynska, "Emerging strategies to enhance homing and engraftment of hematopoietic stem cells," Stem Cell Reviews, vol. 12, no. 1, pp. 121-128, 2016.

[32] T. C. Luis, C. S. Tremblay, M. G. Manz, T. E. North, K. Y. King, and G. A. Challen, "Inflammatory signals in HSPC development and homeostasis: too much of a good thing?," Experimental Hematology, vol. 44, no. 10, pp. 908-912, 2016.

[33] L. G. Schuettpelz and D. C. Link, "Regulation of hematopoietic stem cell activity by inflammation," Frontiers in Immunology, vol. 4, 2013.

[34] K. Ishihara and T. Hirano, "Molecular basis of the cell specificity of cytokine action," Biochimica et Biophysica Acta (BBA) Molecular Cell Research, vol. 1592, no. 3, pp. 281-296, 2002.

[35] E. M. Pietras, C. Mirantes-Barbeito, S. Fong et al., "Chronic interleukin-1 exposure drives haematopoietic stem cells towards precocious myeloid differentiation at the expense of self-renewal," Nature Cell Biology, vol. 18, no. 6, pp. 607-618, 2016.

[36] R. N. Apte and E. Voronov, "Is interleukin-1 a good or bad 'guy' in tumor immunobiology and immunotherapy?," Immunological Reviews, vol. 222, no. 1, pp. 222-241, 2008.

[37] C. J. H. Pronk, O. P. Veiby, D. Bryder, and S. E. W. Jacobsen, "Tumor necrosis factor restricts hematopoietic stem cell activity in mice: involvement of two distinct receptors," The Journal of Experimental Medicine, vol. 208, no. 8, pp. 1563-1570, 2011.

[38] V. I. Rebel, S. Hartnett, G. R. Hill, S. B. Lazo-Kallanian, J. L. Ferrara, and C. A. Sieff, "Essential role for the p 55 tumor necrosis factor receptor in regulating hematopoiesis at a stem cell level," The Journal of Experimental Medicine, vol. 190, no. 10, pp. 1493-1504, 1999.

[39] F. Rezzoug, Y. Huang, M. K. Tanner et al., "TNF- $\alpha$ is critical to facilitate hemopoietic stem cell engraftment and function," The Journal of Immunology, vol. 180, no. 1, pp. 4957, 2008.

[40] S. S. Chung, Y. Wu, Q. Okobi et al., "Proinflammatory Cytokines IL-6 and TNF- $\alpha$ increased telomerase activity through NF- $\kappa$ B/STAT1/STAT3 activation, and withaferin a inhibited the signaling in colorectal cancer cells," Mediators 
of Inflammation, vol. 2017, Article ID 5958429, 11 pages, 2017.

[41] N. B. Azouna, L. Berraeis, Z. Regaya, and F. Jenhani, "Immunophenotyping of hematopoietic progenitor cells: comparison between cord blood and adult mobilized blood grafts," World Journal of Stem Cells, vol. 3, no. 11, pp. 104-112, 2011.

[42] A. V. Panteleev and I. A. Vorobjev, "Expression of early hematopoietic markers in cord blood and mobilized blood," Tsitologiia, vol. 54, no. 10, pp. 774-782, 2012.

[43] P. Proost, A. Mortier, T. Loos et al., "Proteolytic processing of CXCL11 by CD13/aminopeptidase $\mathrm{N}$ impairs CXCR3 and CXCR7 binding and signaling and reduces lymphocyte and endothelial cell migration," Blood, vol. 110, no. 1, pp. 37-44, 2007.

[44] J. Wulfaenger, S. Niedling, D. Riemann, and B. Seliger, "Aminopeptidase N (APN)/CD13-dependent CXCR4 downregulation is associated with diminished cell migration, proliferation and invasion," Molecular Membrane Biology, vol. 25, no. 1, pp. 72-82, 2008.

[45] K. Sekine, H. Fujii, and F. Abe, "Induction of apoptosis by bestatin (ubenimex) in human leukemic cell lines," Leukemia, vol. 13, no. 5, pp. 729-734, 1999.

[46] E. H. Estey, "Acute myeloid leukemia: 2013 update on riskstratification and management," American Journal of Hematology, vol. 88, no. 4, pp. 318-327, 2013.

[47] C. Caux, C. Favre, S. Saeland et al., "Potentiation of early hematopoiesis by tumor necrosis factor-alpha is followed by inhibition of granulopoietic differentiation and proliferation," Blood, vol. 78, no. 3, pp. 635-644, 1991.

[48] Y. Yan, X. Zuo, and D. Wei, "Concise review: emerging role of CD44 in Cancer stem cells: a promising biomarker and therapeutic target," Stem Cells Translational Medicine, vol. 4, no. 9, pp. 1033-1043, 2015.

[49] J. Li, X. M. Zha, R. Wang et al., "Regulation of CD44 expression by tumor necrosis factor- $\alpha$ and its potential role in breast cancer cell migration," Biomedicine \& Pharmacotherapy, vol. 66, no. 2, pp. 144-150, 2012.

[50] N. Alakel, D. Jing, K. Muller, M. Bornhauser, G. Ehninger, and R. Ordemann, "Direct contact with mesenchymal stromal cells affects migratory behavior and gene expression profile of CD133+ hematopoietic stem cells during ex vivo expansion," Experimental Hematology, vol. 37, no. 4, pp. 504$513,2009$.

[51] D. Jing, A. V. Fonseca, N. Alakel et al., "Hematopoietic stem cells in co-culture with mesenchymal stromal cells-modeling the niche compartments in vitro," Haematologica, vol. 95, no. 4, pp. 542-550, 2010.

[52] M. Z. Ratajczak, "A novel view of the adult bone marrow stem cell hierarchy and stem cell trafficking," Leukemia, vol. 29, no. 4, pp. 776-782, 2015.

[53] L. A. Ortiz, F. Gambelli, C. McBride et al., "Mesenchymal stem cell engraftment in lung is enhanced in response to bleomycin exposure and ameliorates its fibrotic effects," Proceedings of the National Academy of Sciences of the United States of America, vol. 100, no. 14, pp. 8407-8411, 2003.
[54] L. A. Ortiz, M. DuTreil, C. Fattman et al., "Interleukin 1 receptor antagonist mediates the anti-inflammatory and antifibrotic effect of mesenchymal stem cells during lung injury," Proceedings of the National Academy of Sciences of the United States of America, vol. 104, no. 26, pp. 11002-11007, 2007.

[55] H. Yagi, A. Soto-Gutierrez, N. Navarro-Alvarez et al., "Reactive bone marrow stromal cells attenuate systemic inflammation via sTNFR1," Molecular Therapy, vol. 18, no. 10, pp. 1857$1864,2010$. 


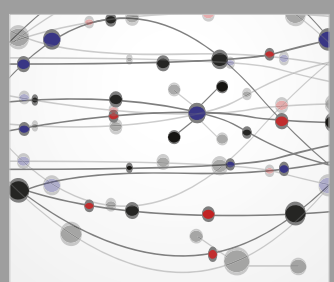

The Scientific World Journal
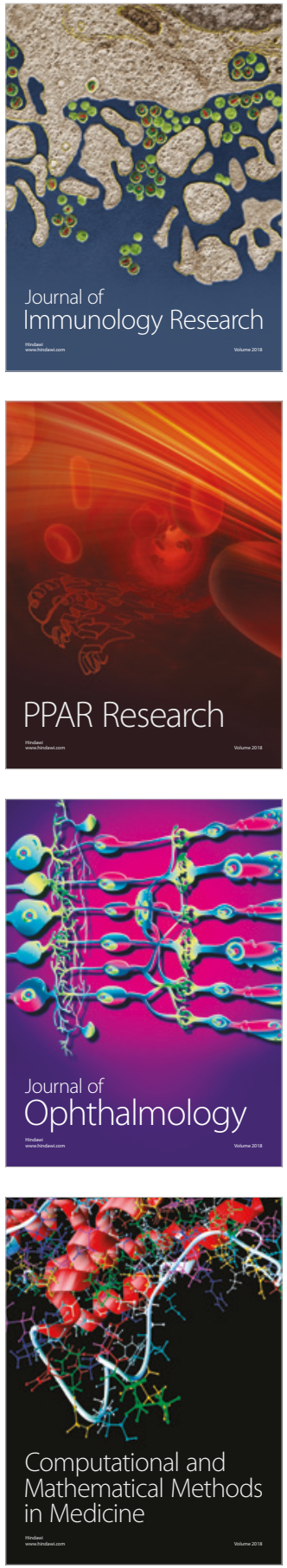

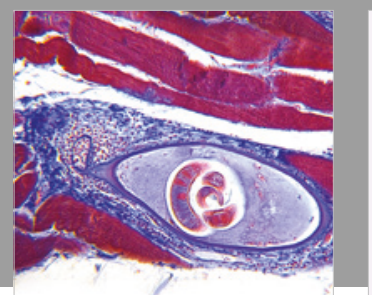

Gastroenterology Research and Practice

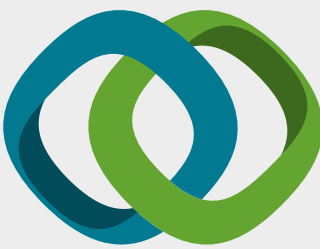

\section{Hindawi}

Submit your manuscripts at

www.hindawi.com
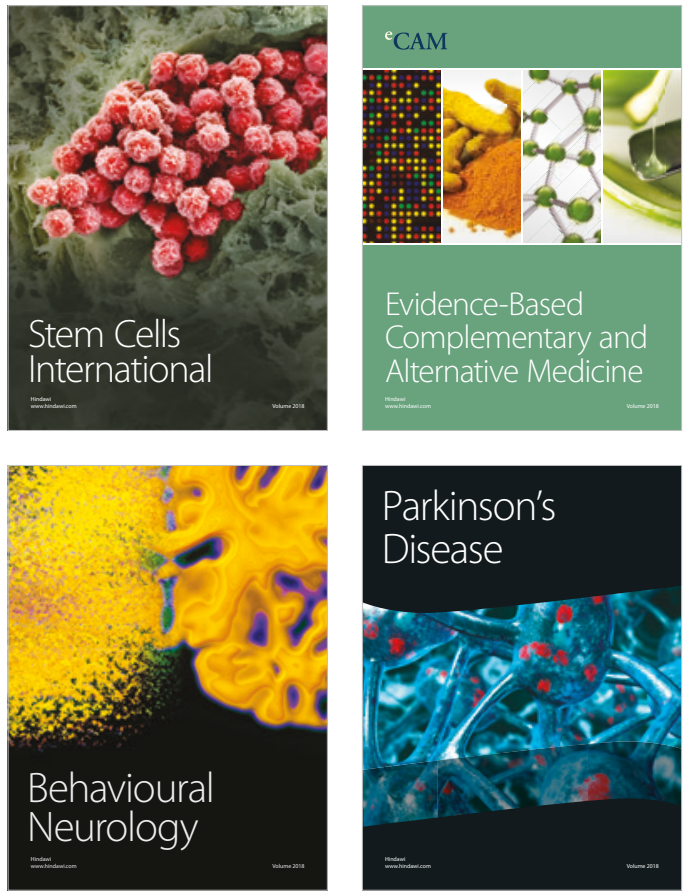

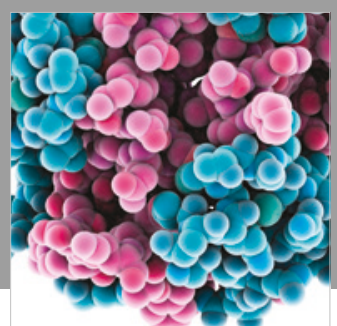

ournal of

Diabetes Research

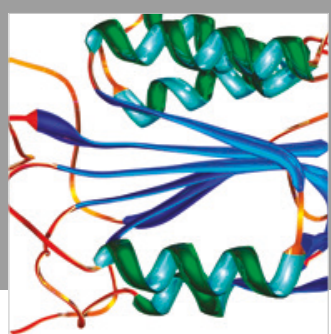

Disease Markers
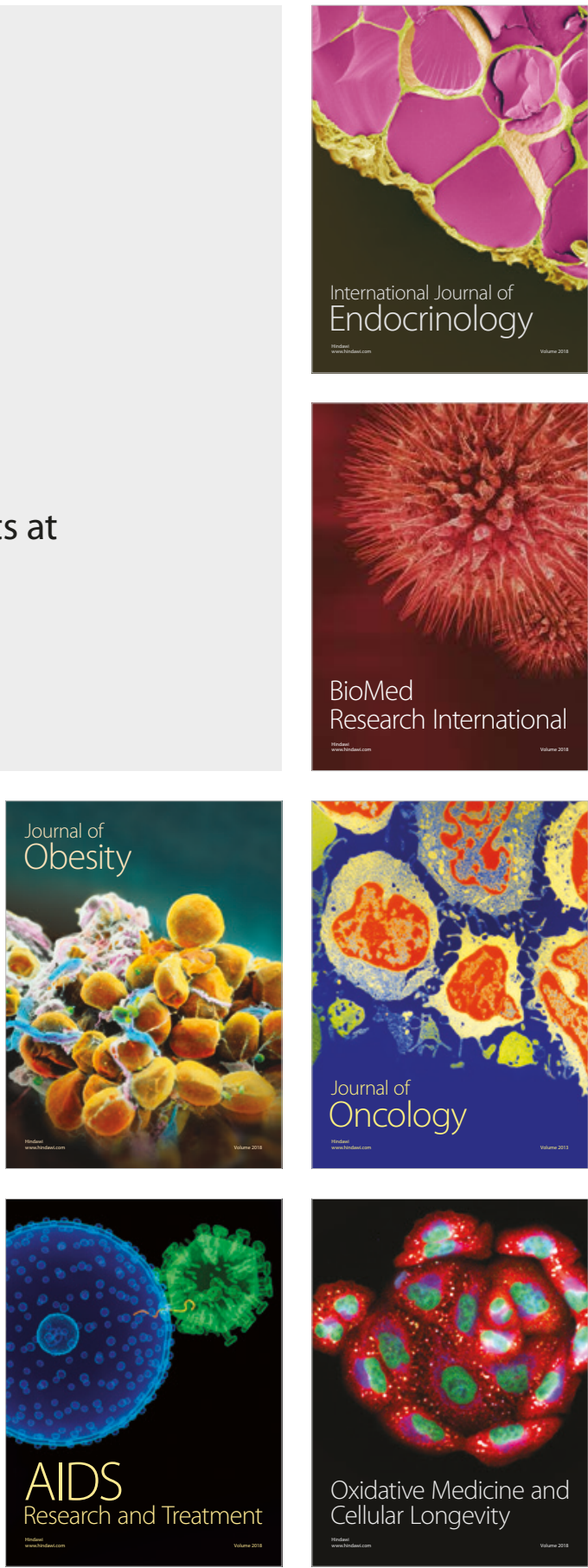